\title{
EXPERIMENTS AND MODELLING OF CAVITATING FLOWS IN VENTURI: ATTACHED SHEET CAVITATION
}

\author{
S. Barre*, J. Rolland, G. Boitel, E. Goncalves, R. Fortes Patella \\ Laboratoire des Ecoulements Géophysiques et Industriels (LEGI - CNRS -INPG - UJF), BP53, 38041 Grenoble, France
}

\begin{abstract}
Correlated experimental and numerical studies were carried out to analyse cavitating flows and to describe the twophase flow structures of attached sheet cavitation in Venturi geometries. New double optical probe measurements were performed and special data processing methods were developed to estimate void ratio and velocity fields for cold water flows.

By applying a computational method previously developed in LEGI Laboratory based on the code Fine ${ }^{\mathrm{TM}} /$ Turbo and on a barotropic approach, several steady calculations were performed in cold water cavitating flows. Local and global analyses were proposed based on comparisons between experimental and numerical results.
\end{abstract}

\section{KEYWORDS: Cavitation/Modelling/Optical Probe/Two-Phase Flow}

\section{INTRODUCTION}

The present work follows previous experimental and numerical studies carried out by the Turbomachinery and Cavitation team of LEGI (Grenoble, France) [Stutz and Reboud, [1,2,3,4]; Pouffary et al, [5,6] ].

The main purpose of this paper is to describe the two-phase flow structure of a "quasi-stable" attached cavitation sheet both by experiments and computational fluid dynamics (CFD) mean. An accurate description of the two-phase structure is essential to describe the cavitation process occurring in this kind of flow. Furthermore, confrontation between experimental and CFD results are essential to validate and to improve physical and numerical cavitating flow models.

Because of cavitating flow complexity, the main challenges are to obtain experimentally void ratio and velocity fields inside the sheet, and to perform reliable numerical simulations.

Experimental studies in cavitation sheet were often limited to the measurements of global flow characteristics or eventually to some local data in the surrounding liquid flow area. Previous work mainly focused on pressure and temperature fields at the wall, external flow velocity and geometrical description of the cavity shapes. See for example Laberteaux et al. [7], Le et al. [8] and Callenaere et al. [9] among others. At the opposite the two-phase flow structure of attached cavities has been the subject of very few measurements. Let us recall the work of Kamono et al. [10] who performed 
velocity measurements in natural and ventilated cavities using a double hot-wire anemometer on a foil section. Bubble detection was also performed by Ceccio and Brennen [11] who used silver epoxy electrodes flush-mounted on an hydrofoil surface for individual bubble velocity detection.

More recently some other techniques have been applied to the investigation of such diphasic flows. Iyer and Ceccio [12] used Fluorescent Particle Image Velocimetry (PIV-LIF) to obtain both the mean velocity field and the Reynolds stress tensor in a cavitating turbulent free shear layer. Dular et al. [13] also used PIV-LIF technique to obtain the velocity field inside and outside of the cavitation sheet existing on a hydrofoil model. It is clear that PIV-LIF is a particularly performing tool to obtain mean and turbulent velocity fields. However it is a very expensive and sophisticated technique and it is almost impossible to perform precise local void ratio measurements with such technology. It must then be coupled to another measurement system to obtain this information in the studied flow.

This can be done by using X-Ray absorption technique which is a very performing tool to measure void ratio in two-phase cavitating flows. Using this system we can obtain a very reliable estimation of the void ratio field. This technique may be used with two kind of data processing methods:

- Firstly, obtention of spatially integrated void ratio temporal variations. This process was used by Stutz et al. [14] to qualify the dynamic behaviour of a cavitation sheet over a venturi with strong adverse pressure gradient leading to a periodic pulsation of the rear part of the sheet.

- Secondly, obtention of the spatial distribution of temporally averaged void ratio by a tomographic reconstruction algorithm of the void ratio field. Results on a 3D very complex geometry (Rocket turbopump inducer) were obtained by Hassan et al. $[15,16]$. They described the spatial and temporal repartition of the void ratio over the entire flow field in a real rocket engine turbopump inducer.

However the X-Ray absorption technique is not able to measure exactly the mean and turbulent velocity fields at a sufficiently fine spatial resolution to obtain mean and fluctuating values compatibles with Reynolds averaging hypothesis.

It is clear that both the PIV-LIF and X-Ray absorption techniques are presumably one of the best possible choice available to-day to obtain velocity and void-ratio fields in cavitating two-phase flows. The main couterpart being that they are very expensive and that they must be used in a synergy process to obtain data both on velocity and void ratio fields. At the opposite, the use of double optical probe is a very cheap method to obtain, from only one measurement, quite good data about both velocity and void ratio fields. We then decide, in the present work, to use a double optical probe (as in Stutz and Reboud [2] and Stutz [4] ) to perform both void ratio and longitudinal velocity measurements. This technique has been chosen among other possibilities (see Stutz and Reboud [1] for a review) because it has proven to be well adapted to the particular flow configuration under study. 
The present work is an extension of Stutz [4] one. The experimental technique has been improved and particularly a new algorithm has been introduced to perform velocity fields statistics computations. Furthermore, a comparison with CFD results has been done to obtain a better understanding and modelling of cavitation phenomena as was initiated by Reboud et al. $[17,18]$ and Pouffary et al. [5,6,19].

The studies are led in collaboration with the French space agency (CNES), the rocket engine division of Snecma, and Numeca International. The main final aims are the analyses of cavitating flows in the rocket engine turbopump inducers, where the run fluids are cryogenic fluids, as LH2 and LOx.

In this paper, we present experimental and numerical studies performed in the case of cold water. In order to facilitate and to carry out local measurements and analyses, cavitating flows inside of space turbopump inducers are simulated by Venturi geometries.

Section 1 presents the experimental device used for recent tests in cold water. Section 2 describes the new data processing methods developed to evaluate, from measurements by double optical probes, the void ratio and velocity fields in cavitating flows.The experimental approach has been applied for a Venturi geometry (named "Venturi 4"), where the cavitating flow is characterized by a quasi-steady attached sheet cavitation. Comparisons with previous experimental results obtained by Stutz [4] are presented in Section 3.

To gain further knowledge concerning cavitating flows, in parallel with experimental studies, twodimensional and three-dimensional models of steady and unsteady cavitation have been developed in LEGI (Coutier et al. [20,21,22]). One of the numerical works results from the integration of a cavitation model in the 3D Navier-Stokes code Fine ${ }^{\mathrm{TM}} /$ Turbo developed by Numeca Int.(Pouffary et al.,[5,6,19]). The cavitation model is represented by a barotropic state law, proposed by Delannoy and Kueny [23] that strongly links the fluid density to the pressure variations.

The numerical model, presented in Section 4, has been applied to simulate water cavitating flow in "Venturi 4" geometry. Global and local analyses based on the comparison between experimental and numerical results are presented in Section 5.

\section{EXPERIMENTAL DEVICE}

The experimental device includes mainly a test loop and a sensor (a double optical probe) associated with an acquisition module.

\subsection{The test loop}

The Venturi type test section of the CREMHYG (INPG Grenoble) cavitation small tunnel was dimensioned and designed to simulate cavitating flows developing on the blades of space turbopump inducers. The hydraulic system (Figure 1) is composed of a circulating pump and of a free surface 
tank, used to impose the reference pressure in the circuit and to resorb dissolved gases. The flow rate, controlled by a computer, is measured by means of an electromagnetic flowmeter. The pressure within the flow is measured by two sensors located in the free surface tank and in the entry section of the Venturi $\left(\mathrm{S}_{\mathrm{i}}\right)$. The adjustment of the pressure in the circuit is obtained by managing the air pressure over the free surface of the tank by means of a vacuum pump. The measurement accuracies are evaluated to be:

$$
\begin{aligned}
& \Delta \mathrm{Q} / \mathrm{Q}= \pm 0,25 \% \text { for flow rate } \\
& \Delta \mathrm{P}= \pm 0,05 \text { bar for the pressure. }
\end{aligned}
$$

The Venturi test section consists in parallel sidewalls generating rectangular cross sections. The bottom wall can be equipped with several interchangeable Venturi profiles allowing the study of cavitation on various geometries. These profiles are equipped to receive pressure sensors, temperature sensors, or double optical probe.

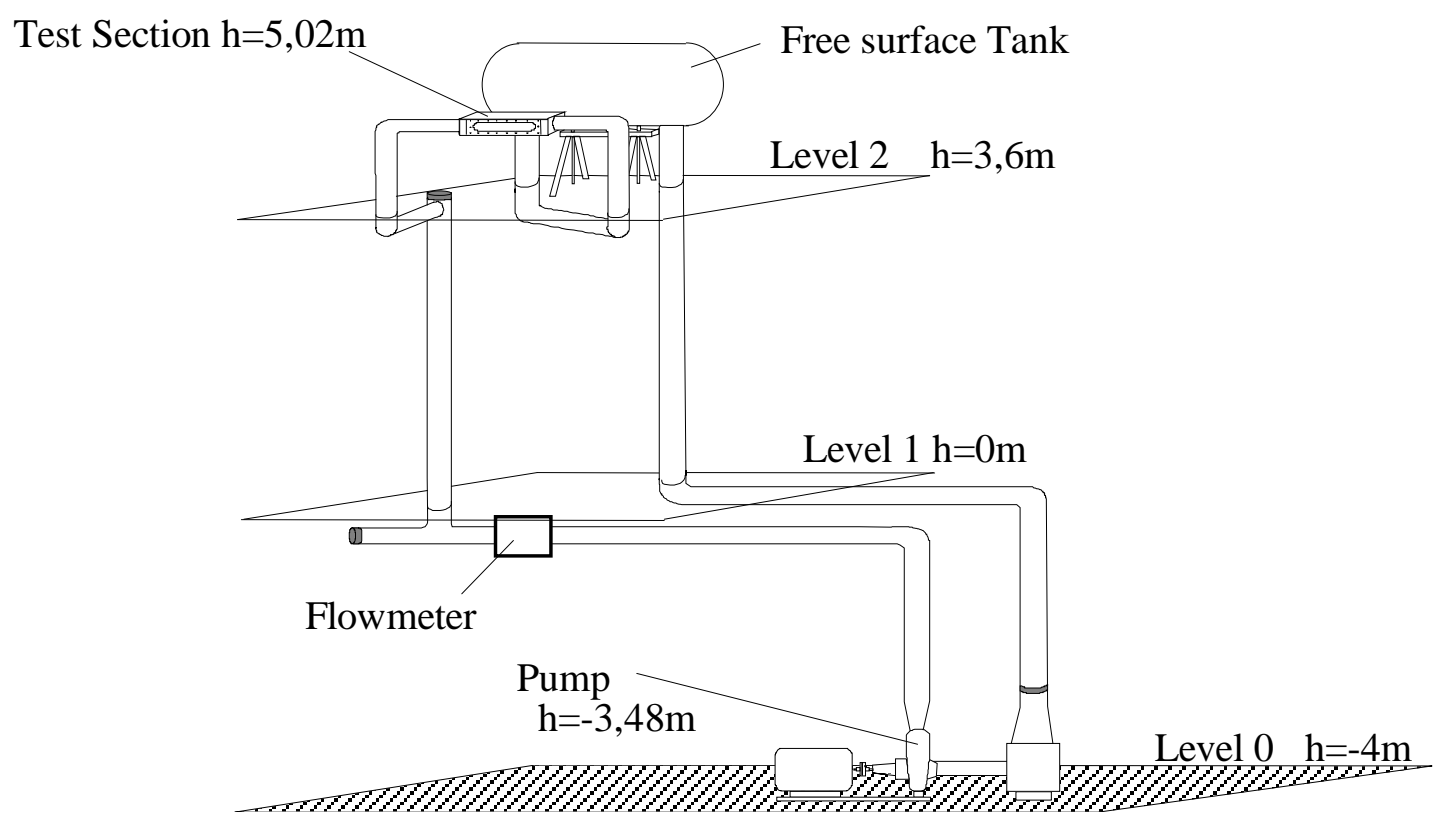

Figure $\mathbf{N}^{\circ} 1$ : Schematic view of the hydraulic set-up

In the present study, we use a profile with a convergence angle of $4.3^{\circ}$ and a divergence angle of $4^{\circ}$, illustrated in Figure 2. The edge forming the throat of the Venturi is used to fix the separation point of the cavitation cavity. This profile is characterized by the following geometrical data:

Inlet section: $\mathrm{S}_{\mathrm{i}}=50 \times 44 \mathrm{~mm}^{2}$ (where the reference pressure is measured);

Throat section: $S_{\text {throat }}=43,7 \times 44 \mathrm{~mm}^{2}$;

Length of the test section (chord): $\mathrm{L}_{\text {ref }}=252 \mathrm{~mm}$. 
This profile is equipped with five probing holes to take various measurements such as the local void ratio, instantaneous local speed and pressure. Their horizontal positions $X_{I}$ from the throat of the Venturi are:

$$
\begin{gathered}
\mathrm{X}_{1}=5.1 \mathrm{~mm} ; \mathrm{X}_{2}=20.9 \mathrm{~mm} ; \mathrm{X}_{3}=38.4 \mathrm{~mm} ; \\
\mathrm{X}_{4}=55.8 \mathrm{~mm} ; \mathrm{X}_{5}=73.9 \mathrm{~mm} .
\end{gathered}
$$

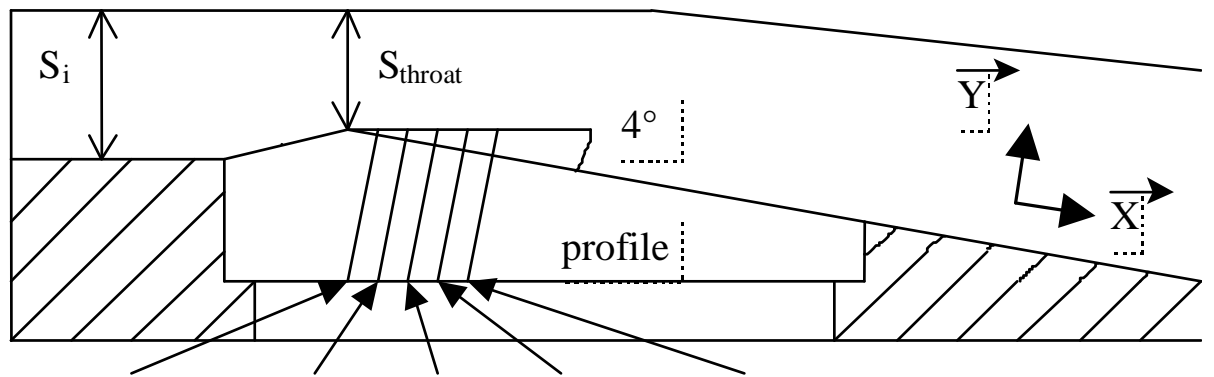

Station 1 Station 2 Station 3 Station 4 Station 5

Figure $\mathrm{N}^{\circ}$ 2: Schematic view of the Venturi profile

A photograph of this test section is shown in Figure 3.

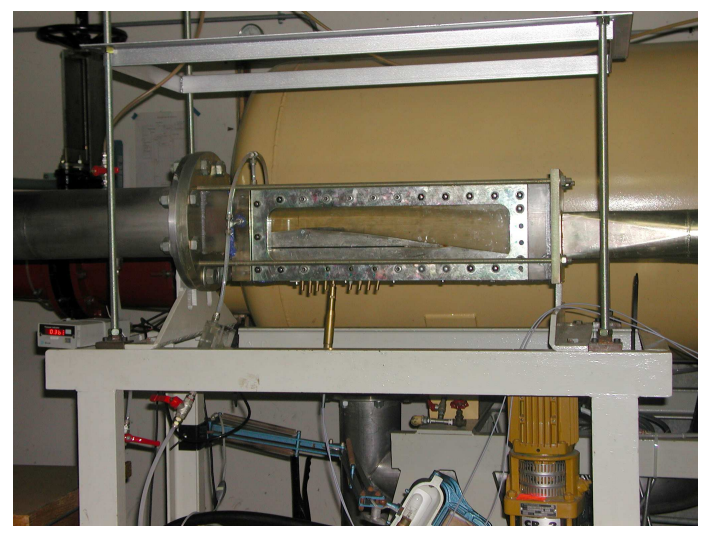

Figure $N^{\circ}$ 3: Venturi test section

The selected operation point of the hydraulic system is the same used by Stutz et al. [1,4]. It is characterized by the following physical parameters:

$\mathrm{U}_{\text {inlet }}=10.8 \mathrm{~m} / \mathrm{s}$ : inlet speed

$\mathrm{Q}=0,02375 \mathrm{~m}^{3} / \mathrm{s}$ : flow imposed in the circuit by the circulating pump

$\mathrm{P}_{\mathrm{tank}}=0,713$ bar: pressure measured in the tank

$\mathrm{P}_{\text {inlet }}=36000 \mathrm{~Pa}$ : pressure in the inlet section

$\mathrm{N}_{\text {pump }}=506 \mathrm{rpm}$ : rotating speed of the circulating pump. 
With these parameters, we obtain a cavity length $\mathrm{L}$ ranging between $70 \mathrm{~mm} \leq \mathrm{L} \leq 85 \mathrm{~mm}$, and having a relatively stable aspect, as shown on the Figure 4.

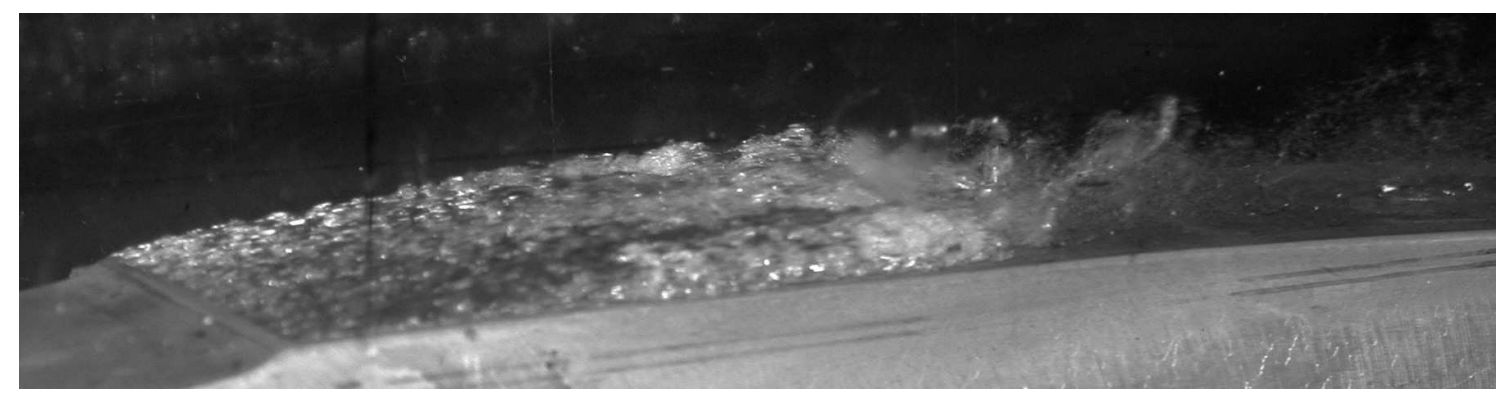

Figure $N^{\circ}$ 4: Photograph of the cavity

\section{1.b. The sensor}

To evaluate void ratio and velocity fields inside of the cavity, we have used a double optical probe. The double optical probe is an intrusive sensor composed by two mono-probes functioning in a independent way but mechanically connected one to other. Each probe consists in an optical fiber ending in a frayed Sapphire point. This point is plunged in the flow. An infra-red radiation is injected at an end of fiber. The part of this signal that is reflected at the tip of the probe is converted into electric signal by an optoelectronic module.

The luminous ray is absorbed by the fluid when the tip of the probe is surrounded by liquid; in this case, the measured tension is minimal. When the tip is in a pure vapour zone, the measured tension is maximal. The signal analysis allows determining the phase (liquid or gas) of the flow structures around the probe. This information gives access to the local time fraction of the vapour phase (void rate) and the convection speed of the vapour structures. We use an optical probe made of two optical fibers of $80 \mu \mathrm{m}$ diameter and with the frayed ends. The inter-tips distance is $1,05 \mathrm{~mm} \pm$ 0,02 (see Figure 5).

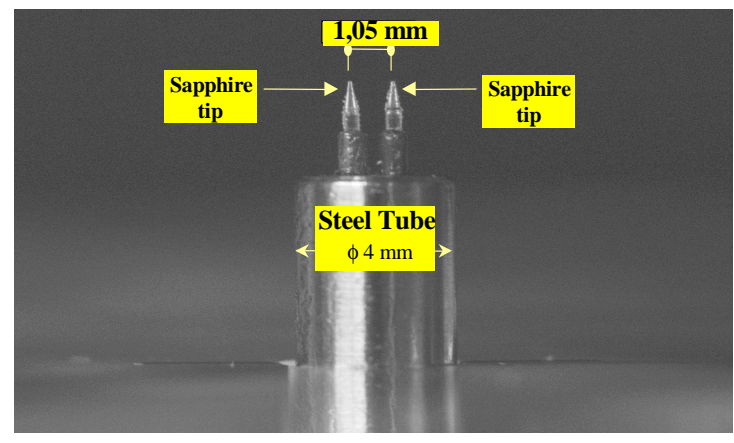

Figure $\mathbf{N}^{\circ} 5$ : Double optical probe

The double probe is introduced into the cavitation sheet using a threaded interface assembled in the boreholes of the profile (also called "stations"). A graduated sliding gauge allows to measure the 
vertical displacement of the probe with an accuracy of $\Delta \mathrm{Y}= \pm 0,05 \mathrm{~mm}$. The optical signals obtained by the double probe are transformed into electric signals by an optoelectronic module. The values of the gains and the zeros of the apparatus are tuned in order to obtain an exit signals of $\pm 1 \mathrm{~V}$ amplitude. Acquisitions are carried out on a fast A/D data acquisition board NI-DAQ PCI-6110E and a microcomputer. For each acquisition we recorded 6 million points per way (one way by optical probe), with a sampling rate of $100 \mathrm{Khz}$ (corresponding to a time of 60 seconds acquisition per measurement). For each Y position of the optical probe in the Venturi (between ten and fifteen per station), five successive measurements are taken. It generates 30 million points of measurement per position in the cavity corresponding to an observation time of 300s. This new experimental tool increases clearly the overall performance of the entire system as compared to the work performed by Stutz in the same device (Stutz [4]). The main differences are:

-At first, the double optical probe was changed by decreasing the distance $\Delta \mathrm{x}$ between the two probes. We now use a $\Delta \mathrm{x}=1.05 \mathrm{~mm}$ instead of $2.02 \mathrm{~mm}$ in Stutz's experiments. The probe design is also new. We use in the present study, Sapphire tips probes instead of silice ones. The main advantage of such a technology consists in a better robustness of the probe tips avoiding probe breakages when used in very aggressive flows such as re-entrant jets at the bottom of the cavitation sheet.

- the optoelectronics module used in the present experiment remains the same as the one used in Stutz's experiments (Stutz [4]). It has a response time of $1 \mu \mathrm{s}$.

-We can also notice that the observation time was 9s for each measurements in Stutz [4] instead of 300s in the present study. This great increase may lead us to obtain quite better statistics results: particularly, the Velocity Probability Density Functions (PDF) is much more accurately defined.

-The data processing method developed to obtain velocity PDF is based on the concept presented by Stutz [4] but was greatly modified to increase the quality of the PDF computation, as described in the next section.

\section{DATA PROCESSING METHODS}

\section{2.a. Estimation of the local void ratio}

The local void ratio $\alpha$ of a vapour/liquid mixture is defined here as the ratio between the cumulated attendance time of the vapour phase $\sum_{i=1}^{n} T_{\text {vap }} i$ and a given time of observation $T_{\text {tot } \_ \text {obs }}$ in an operation point of the flow. It is given by: 


$$
\alpha=\frac{\sum_{i=1}^{n} T_{\text {vap } \_i}}{T_{\text {tot_obs }}}
$$

The post processing algorithm enables us to process the signal from the optical probe, by distinguishing the vapour phase from the liquid phase according to the value of the measured tension. The maximum tension value $\mathrm{V}_{\max }$ corresponds to the vapour phase and the minimal value $\mathrm{V}_{\min }$ to the liquid phase (Figure 6). In order to be able to estimate the local void ratio, we must fix a threshold in tension $\mathrm{V}_{\text {threshold. }}$. It makes it possible to determine the phase of the fluid around the probe: liquid state if $\mathrm{V}<\mathrm{V}_{\text {threshold }}$ and vapour state if $\mathrm{V}>\mathrm{V}_{\text {threshold. }}$ This threshold is fixed, in this study, according to the parameter:

$$
\beta=\frac{V_{\text {threshold }}-V_{\min }}{V_{\max }-V_{\min }}
$$

The value of this parameter for this kind of flow was gauged by Stutz et al.[1,2,3,4,24] using a $\gamma$ Ray absorption device. They retained a value of $\beta=0.1$ to give correct void ratios for this typical flow pattern. In the present work, we have used this value for the determination of the void ratio.

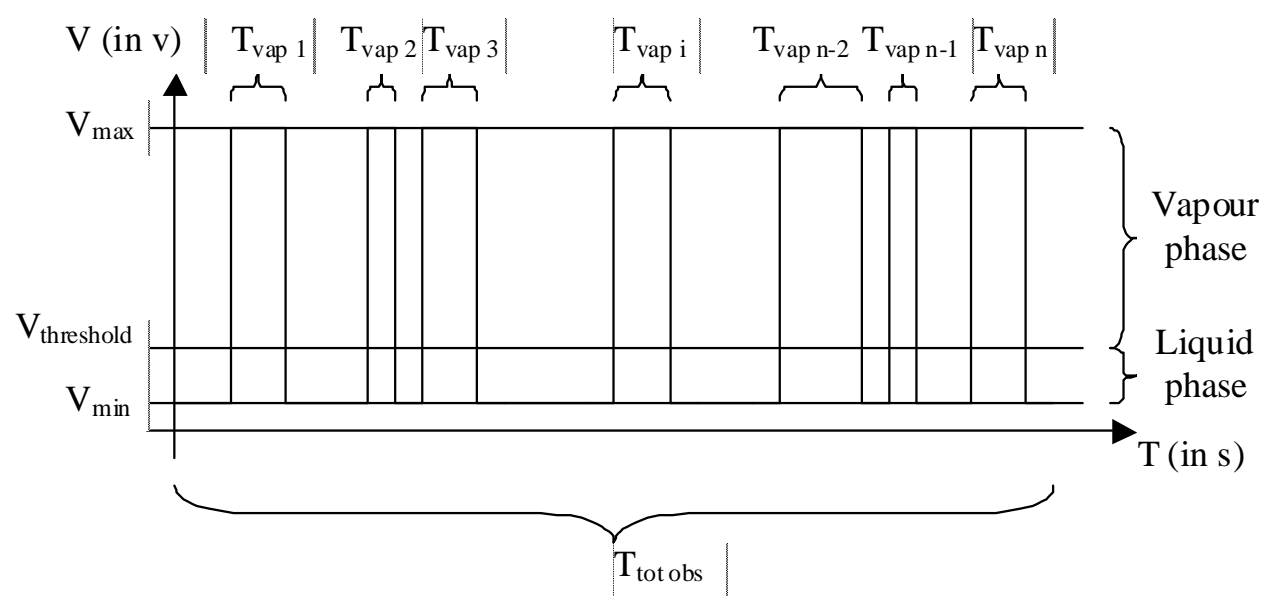

Figure $\mathrm{N}^{\circ}$ 6: Relative positions of the thresholds for void ratio analysis

\section{2.b. Estimation of instantaneous local velocity}

The basic idea used to determine the instantaneous velocities in two-phases flows was firstly developed by Serisawa et al. [25] and Revankar and Ishii [26] and applied by Stutz [4] in the case of cavitating flows. The principle is relatively simple and consists in comparing the transit time of two bubbles successively detected by probe 1 (S1) and probe 2 (S2). If these two transit times are sufficiently close together we may then consider that we have observed consecutively the same bubble on S1 and S2. We can then compute the longitudinal velocity component using the time delay between the beginning of the bubble detection on S1 and the same event on S2. In the present study, we have developed a new algorithm to compute the Velocity Probability Density Function (PDF) which is quite different to the one used by Stutz [4]. The new approach is described in detail hereafter. 
The used optical probe, aligned in the direction of the flow, produces two distinct signals (S1 upstream and S2 downstream). It is possible to deduce the value of the tangential component (parallel with the profile) of the instantaneous local speed by considering the temporal shift between the trace of a bubble passing on the first probe and that of this same bubble passing on the second probe. For this, it is necessary to detect the vapour bubbles. The electric signals of the two optical probes are thus analysed and broken up by introducing two tension thresholds (Figure 7). The low threshold $\mathrm{V}_{\text {low }}$, taken on the rising part of the electric signal, leads us to detect the beginning of the crossing of a vapour bubble. The high threshold $\mathrm{V}_{\text {high }}$ is considered to detect the end of the crossing of the bubble on the downward part of the signal. A bubble is taken into account in the analysis only when these two thresholds are crossed consecutively.

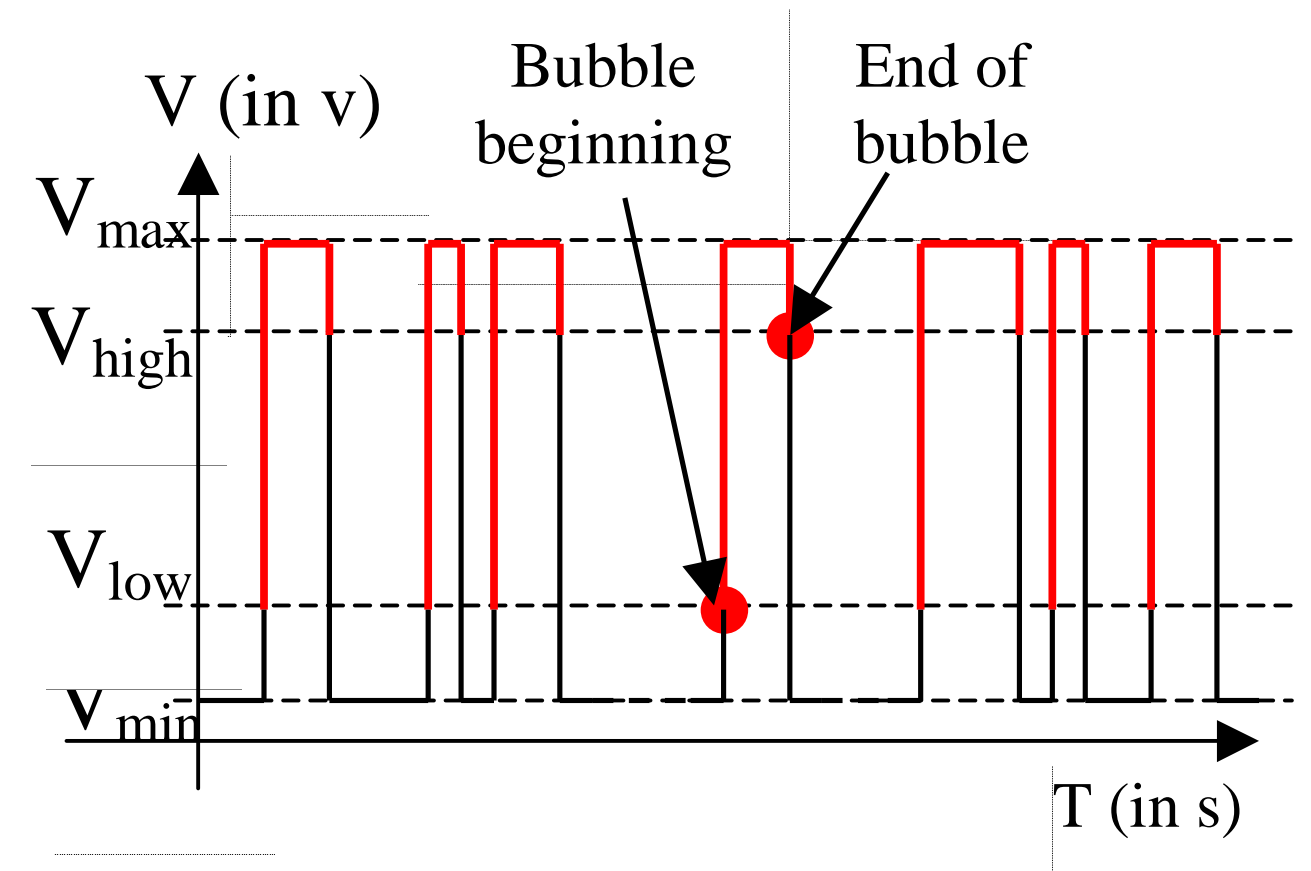

Figure $N^{\circ} 7$ : Bubble localization with threshold method

In the present study, the values of the low and high thresholds are given by considering the parameters:

$$
\beta_{\text {low }}=\frac{V_{\text {low }}-V_{\text {min }}}{V_{\text {max }}-V_{\text {min }}} \text { and } \beta_{\text {high }}=\frac{V_{\text {high }}-V_{\text {min }}}{V_{\text {max }}-V_{\text {min }}}
$$

where $\beta_{\text {low }}=0.2$ and $\beta_{\text {high }}=0.8$ (Stutz et al. $[1,2,4,23]$ ). An analysis of the $\beta$ value influence on the velocity evaluation has been performed and show that for $\beta_{\text {low }}$ and $\beta_{\text {high }}$ close to respectively 0.2 and 0.8 , variations of the $\beta$ value of $\pm 15 \%$ have only a very weak effect on the velocity determination. 
After bubble detection by the both probes, we proceed to the evaluation of the instantaneous velocities. The algorithm used for obtaining these data, as well as the several statistical procedures of treatment applied to evaluate the corresponding Probability Density Functions (PDF) are described hereafter.

First of all, the calculation algorithm reviews all the bubbles detected on the probe S1 (first probe in the direction of the flow). For each bubble seen on S1, a temporal analysis interval will be explored on the signal of the $\mathrm{S} 2$ probe.

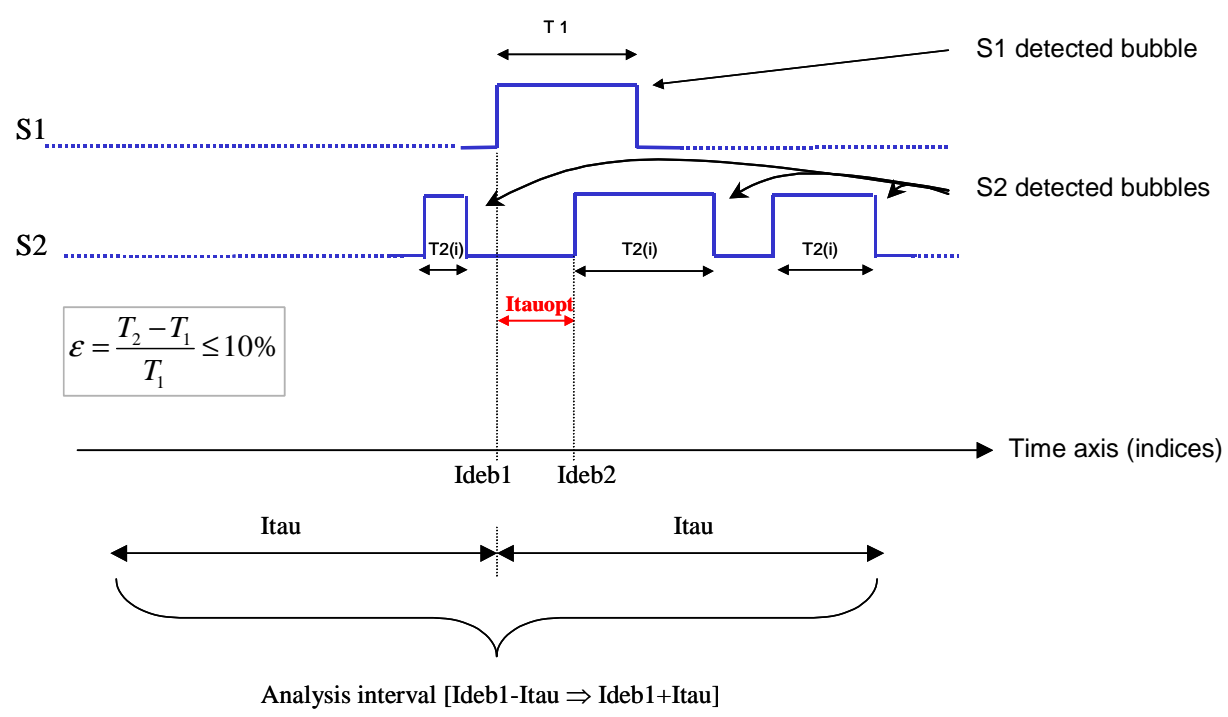

FigureN ${ }^{\circ}$ : Example of Itauopt determination for a given bubble detected on S1

If Idebl is the index corresponding to the beginning of a bubble considered on the $\mathrm{S} 1$ signal, then the analysis interval of the S2 signal will correspond to Ideb1-Itau $<t<I d e b 1+I t a u$, where Itau is the amplitude of the analysis interval. Stutz et al. [1,2,23] proposed to determine Itau by using the value of the peak of the temporal correlation function between the signals resulting from S1 and S2. In the present study, we rather choose an empirically constant value evaluated from the various examinations obtained. This value is fixed here at Itau $=1000$, which corresponds to a temporal analysis interval of $\Delta T= \pm I_{t a u} *$ Tech $= \pm 10 \mathrm{~ms}$, where Tech is the sampling period of the optical probe signals $\left(\right.$ Tech $\left.=1 / \mathrm{Fech}=10^{-5} \mathrm{~s}\right)$ and $\mathrm{F}_{\mathrm{ech}}$ is the sampling frequency. With this $\Delta \mathrm{T}$ range the theoretical corresponding velocity field under examination is: $(-105 \mathrm{~m} / \mathrm{s}<\mathrm{U}<-0.105 \mathrm{~m} / \mathrm{s})$ and $(0.105 \mathrm{~m} / \mathrm{s}<\mathrm{U}<105 \mathrm{~m} / \mathrm{s})$. Absolute value of velocity of $0.105 \mathrm{~m} / \mathrm{s}$ corresponds to Itau=1000 and the value $\mathrm{U}=105 \mathrm{~m} / \mathrm{s}$ corresponds to $\mathrm{Itau}=1$. Thus, we seek on the $\mathrm{S} 2$ probe signal all the existing bubbles in the analysis interval defined. For each one of these bubbles, a test function is calculated as follows: 
We calculate the parameter $\varepsilon=\frac{t_{1}-t_{2}(i)}{t_{1}}$ where $\mathrm{t}_{1}$ is the transit time of the bubble considered on $\mathrm{S} 1$ and $\mathrm{t}_{2}(\mathrm{i})$ the transit times of the bubbles found on $\mathrm{S} 2$ in the analysis interval (see figure $\mathrm{N}^{\circ} 8$ for illustration). From the evaluation of all parameters $\varepsilon$ obtained for all the bubbles found on S2 in the research interval $\Delta \mathrm{T}$, the minimum value $\varepsilon_{\min }$ is determined. The bubble corresponding to the value of $\varepsilon_{\text {min }}$ must now be validated or not according to the value of this test. In this study, the validation criterion corresponds to $\varepsilon_{\min }$ lower or equal to $\varepsilon_{\max }=0.1$, which was empirically determined by a convergence test and a parametric study of the influence of $\varepsilon_{\max }$ on the velocity fields obtained.

By applying this criterion, we rejected approximately $60 \%$ of the detected bubbles. If the bubble is validated on $\mathrm{S} 2$, we compute its temporal shift with the reference bubble of $\mathrm{S} 1$. We then obtain Itauopt $=I d e b 2-I d e b 1$ where Ideb1 and Ideb2 are, respectively, the indices of beginning of bubbles on the signals of the two probes $\mathrm{S} 1$ and $\mathrm{S} 2$ (see figure $\mathrm{N}^{\circ} 8$ for illustration). From Itauopt, we obtain an instantaneous speed value by: $u=\frac{\Delta x}{\text { Itauopt.Tech }}$ where $\Delta x$ is the space difference between the two optical probes $(\Delta \mathrm{x}=1.05 \mathrm{~mm})$ and Tech is the sampling period of the optical probe signals.

By repeating this operation on all the detected bubbles on the $S 1$ probe, we obtain an instantaneous velocity values population, which can be treated in a statistical way to study the dynamics of the flow. For the present study, we obtain typically between 5000 to 70000 values of instantaneous speeds per spatial position of the probes, and this, for an observation time of 300s. It is worth noting that higher is the void ratio, higher is the number of studied bubbles and better is the statistic quality. Following this process we can obtain, for each measurement point in the flow, the Itauopt and velocity PDF. An example of a statistical distribution obtained is given on the Figures 9 (Itauopt) and 10 (velocity). This example corresponds to the point $\mathrm{Y}=1 \mathrm{~mm}$ of the station $\mathrm{N}^{\circ} 2$ (Figure 2). 


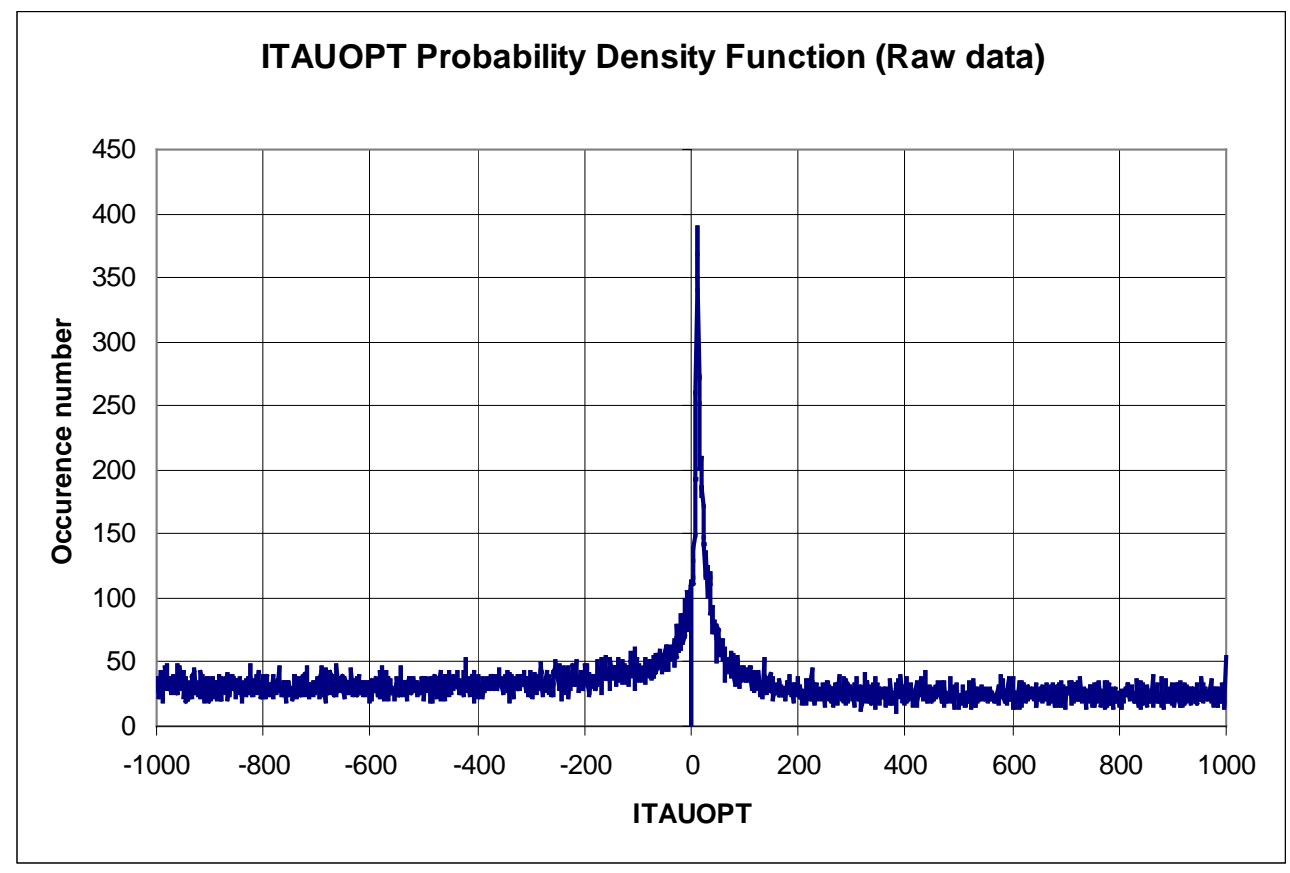

Figure $\mathbf{N}^{\circ}$ 9: PDF of Itauopt values initially obtained (station 2, Y=1mm)

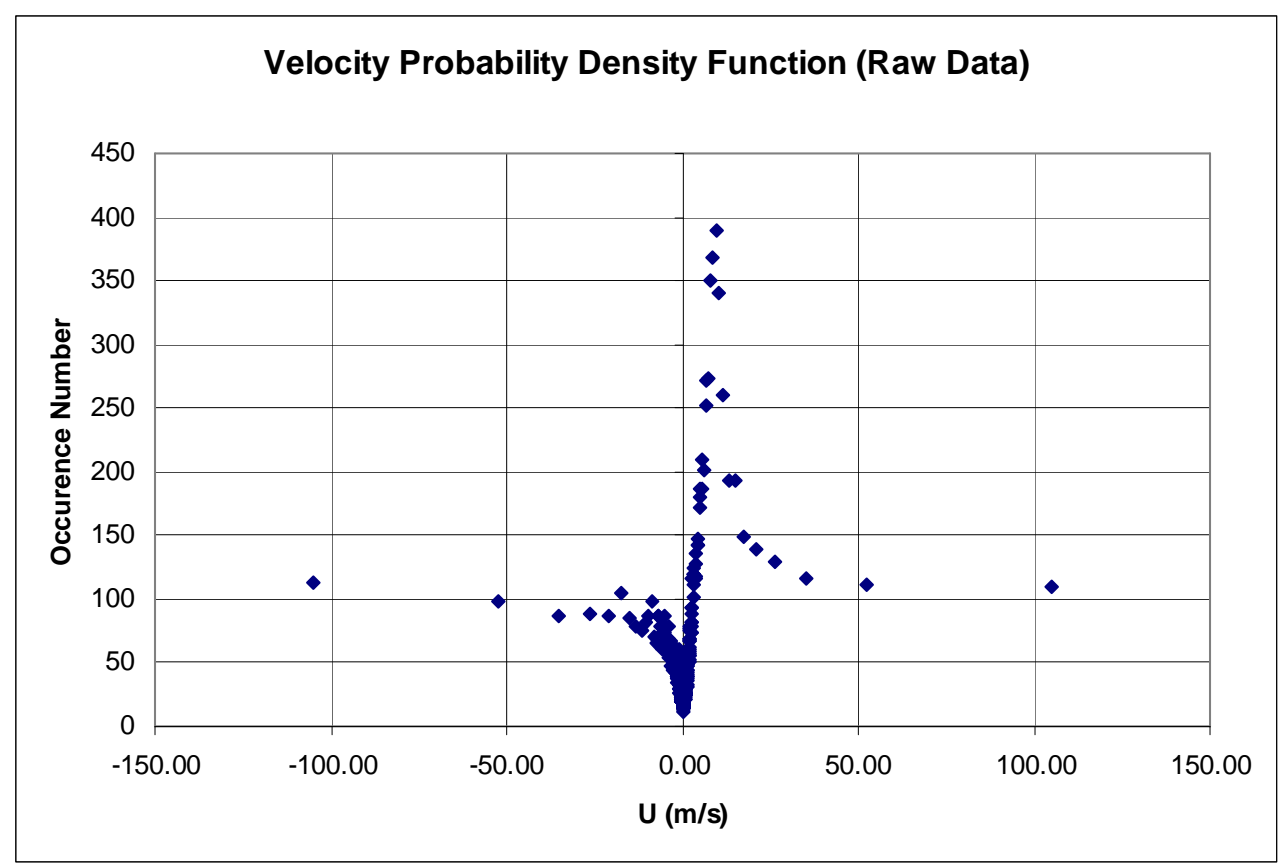

Figure $\mathrm{N}^{\circ} 10$ : PDF of velocity values initially evaluated (station 2, Y=1mm)

We notice an important amount of the Itauopt population around the peak representing the most probable value for the considered measurement point (Figure 9). Moreover, we note, for high absolute values of Itauopt, that the populations do not decrease and tend to reach an asymptotic value. From Figure 10, we can see, near velocity zero value, a regrouping of the occurrences corresponding to the 
two asymptotic branches of the Itauopt distribution. This effect of overpopulation is accentuated by the fact that speed being inversely proportional to Itauopt, so all the high values (in absolute value) for Itauopt correspond to a very small speed range around zero value. This population corresponds in fact to a statistical skew of the algorithm used to evaluate velocity values.

Indeed, following the algorithm, we seek on the S2 signal a bubble whose duration is almost equivalent to the basic bubble located on S1. Then, the probability of finding a solution for the problem increases with the Itau amplitude of the analysis interval. As a matter of fact, if the signals of S1 and S2 were perfectly random, the velocity Probability Density Function would be a Poisson law centered across the zero value speed. This law, which is superimposed on the PDF, must be eliminated. Its contribution on the PDF of the real flow can be removed by using a "neutral" Itauopt PDF, which considers only "background noise". It is determined thanks to the PDF asymptotic parts. Figure 11 illustrates an example of the PDF obtained after Poisson law correction.

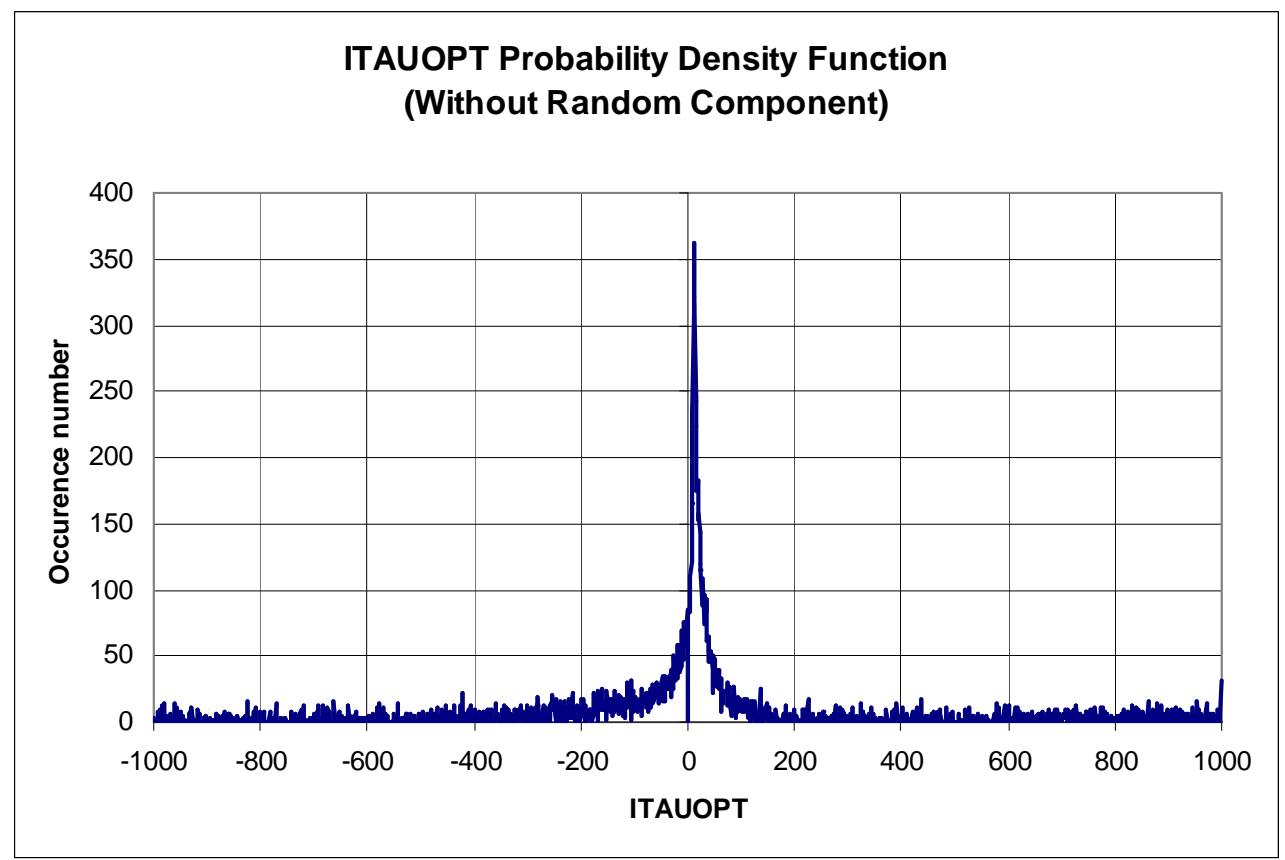

Figure $\mathrm{N}^{\circ}$ 11: Itauopt $\mathrm{PDF}$ obtained by subtraction of random distribution (Poisson law correction)

In spite of this correction, we observe (Figure 12) numerous populations for relatively high speeds absolute values. 


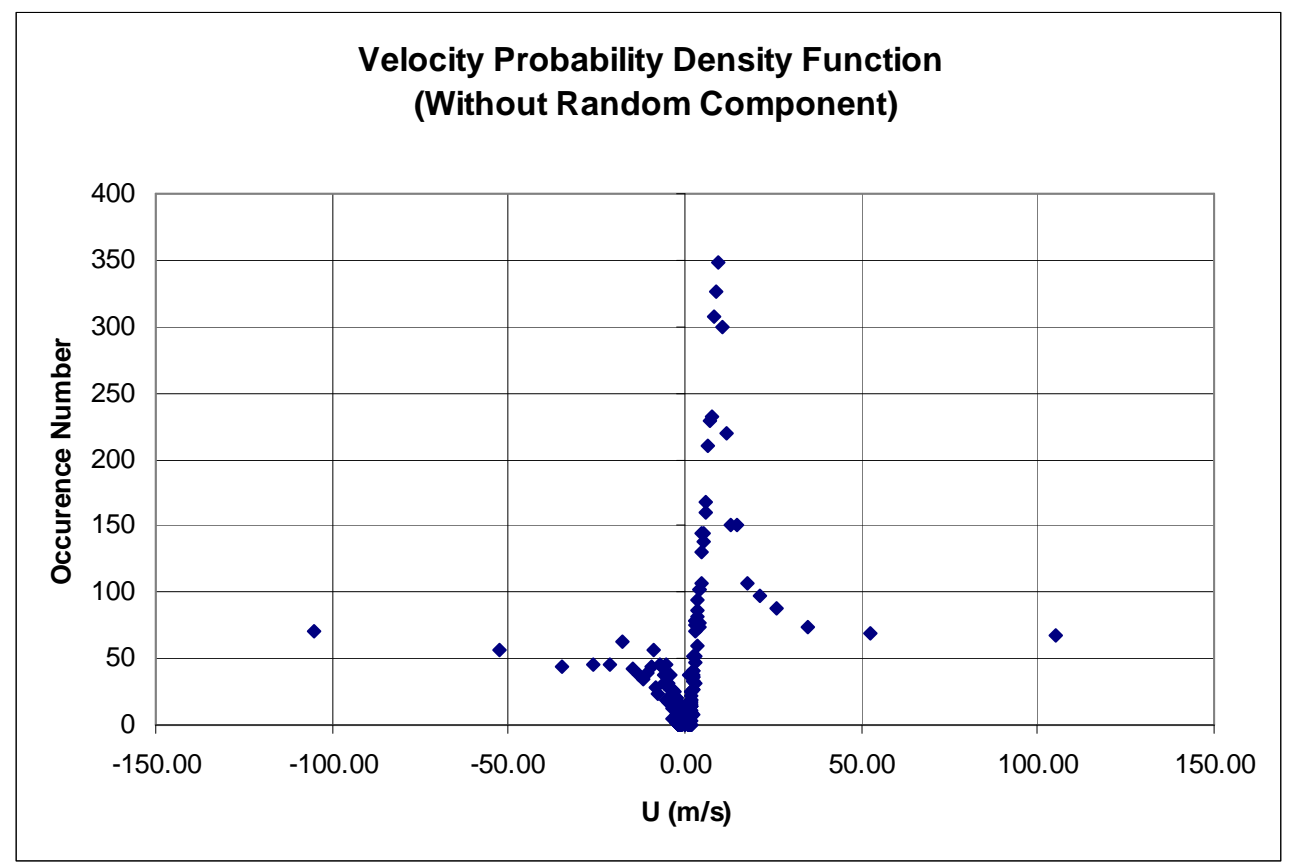

Figure $\mathrm{N}^{\circ}$ 12: Velocity PDF obtained by subtraction of random distribution (Poisson law correction)

This effect is related to the inaccuracy of the method for high speed. Indeed, because Itauopt is an integer number, the measurement method does not give an infinity of possible values for velocity. The accuracy on the velocity evaluation much depends on the Itauopt value. For better visualizing and quantifying this effect, the relative error function

$$
\phi=\frac{U_{\text {Itauopt }+1}-U_{\text {Itauopt }}}{U_{\text {Itaopt }}} \text { was calculated for each value of Itauopt in the range corresponding to }
$$

the considered flow. These results are presented in Figure 13 where the function $\phi$ is plotted for values of $U$ between 1 and $20 \mathrm{~m} / \mathrm{s}$. 


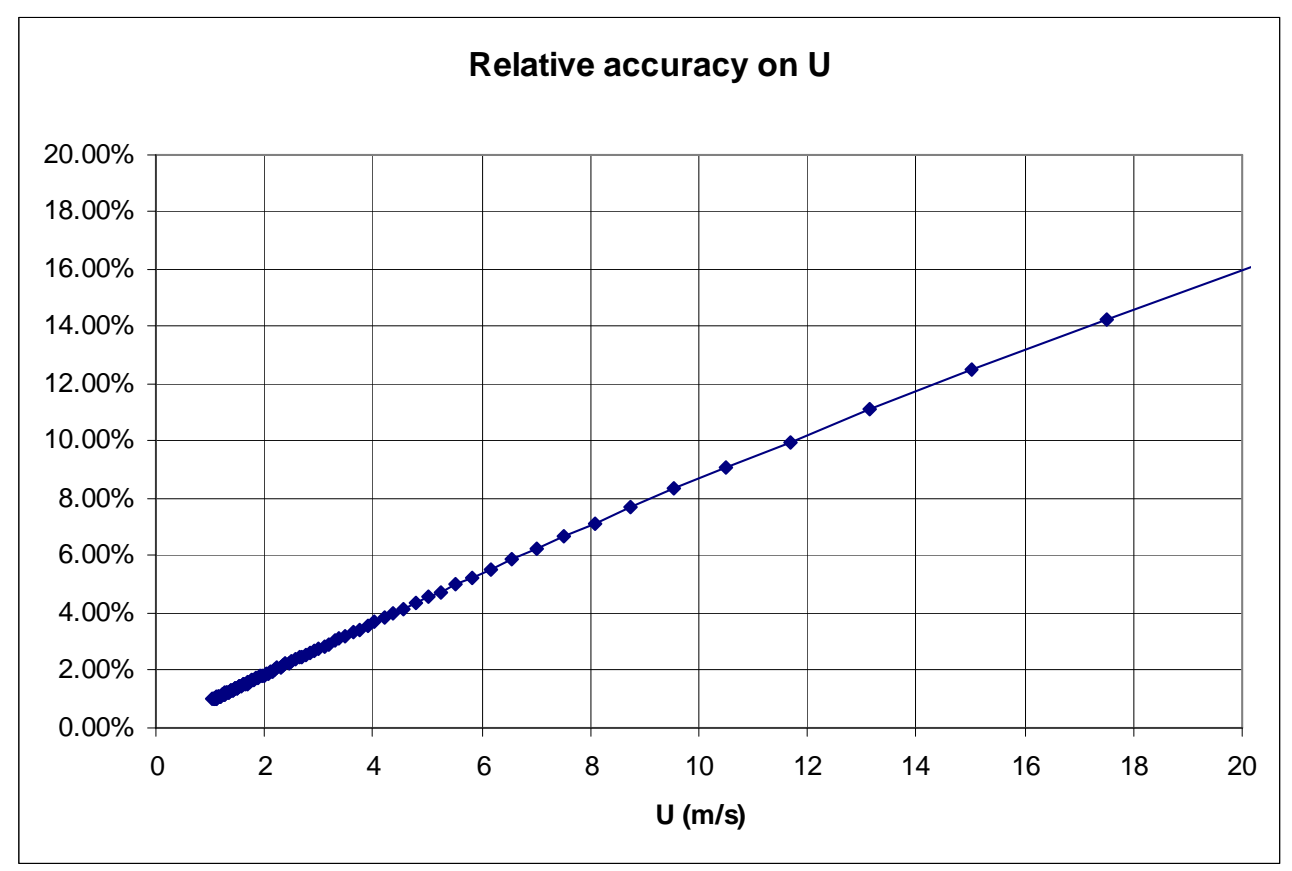

Figure $\mathrm{N}^{\circ}$ 13: Relative error function $\phi$ in the studied velocity range

The accuracy is about $1 \%$ in the neighbourhood of $1 \mathrm{~m} / \mathrm{s}$, but it increases to reach $16 \%$ towards 20 $\mathrm{m} / \mathrm{s}$. Moreover, we note for $U \geq 10 \mathrm{~m} / \mathrm{s}$ that the possible speed distribution is represented by few discrete solutions, which are separated each other by several $\mathrm{m} / \mathrm{s}$.

In fact, the velocity solutions are gathered according to these few possible values, what artificially increases their population. To correct this effect, we distribute the samples at high speed in a more continuous way by proceeding to an oversampling of the PDF. Several assumptions are formulated for this purpose:

* From $|\mathrm{U}| \geq 17 \mathrm{~m} / \mathrm{s}$ we make a speed grid having a $1 \mathrm{~m} / \mathrm{s}$ step, which corresponds roughly to the obtained accuracy near $10 \mathrm{~m} / \mathrm{s}$.

* Between two successive points, we make the assumption that the velocity PDF evolves linearly.

By considering these assumptions, we apply another correction algorithm to the velocity PDF. It consists in generating, between two existing points, fictitious velocity values by respecting a $1 \mathrm{~m} / \mathrm{s}$ step. After that, we distribute all the events corresponding to these two basic points in a linear way between all the fictitious points. For this, we keep the same population ratio between the two basic points before and after correction. Thus, thanks to this correction, we obtain a new oversampled PDF. It should be noted that the form of this new function depends on the selected accuracy (here, $1 \mathrm{~m} / \mathrm{s}$ ).

After these corrections, we obtain typical velocity PDF such as one presented in Figure 14.

By applying this treatment to measurements corresponding to the five stations of the experiment, we have evaluated the velocity PDF for all the probed points. From these data, we are able to describe 
the velocity field inside the cavity. For each point, we keep the most probable value of the PDF to define the local velocity.

Experimental results obtained for flow velocity and void ratio fields have been confronted with ones evaluated by numerical simulation. Main results and analyses are presented here above.

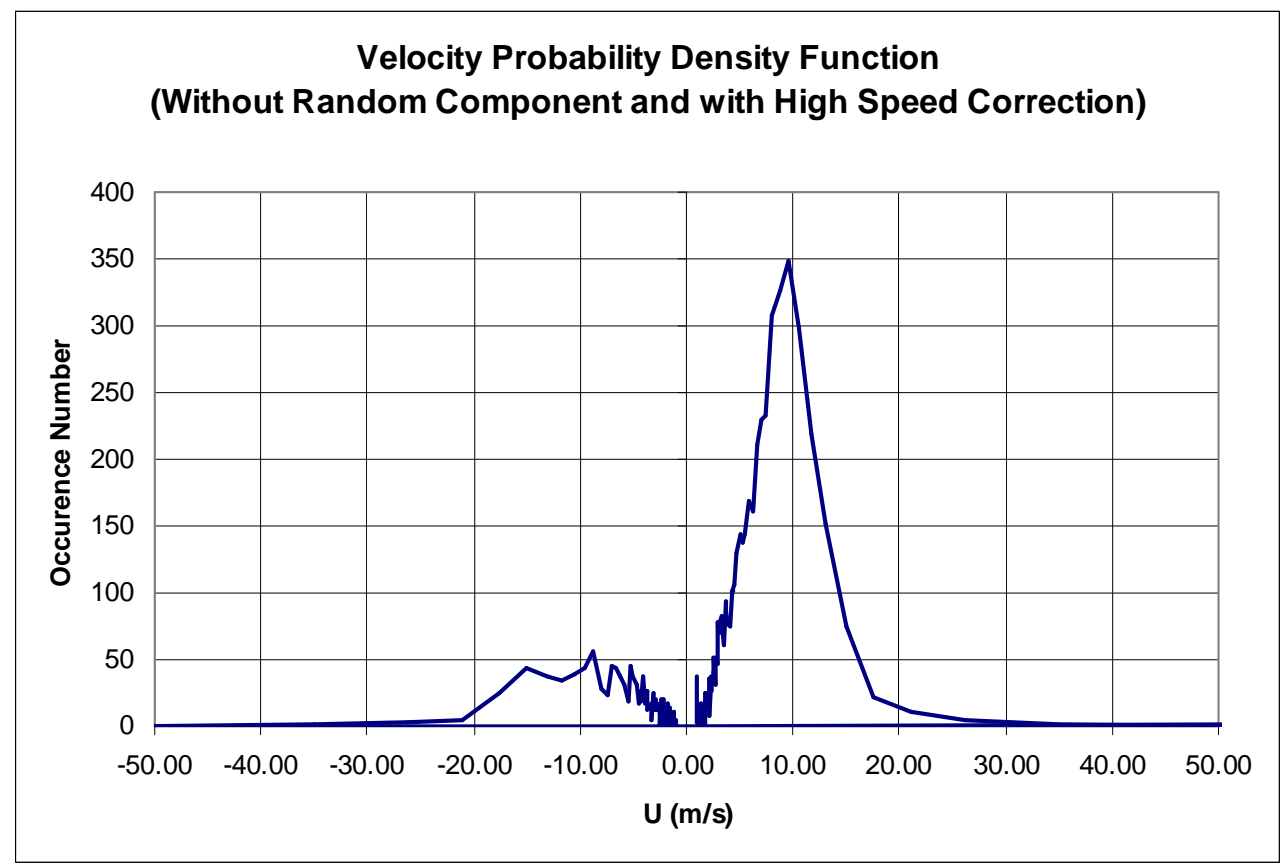

Figure $N^{\circ}$ 14: Final Velocity PDF

(station 2, Y=1mm) ; local velocity evaluated $\mathrm{Vmp}=9.54 \mathrm{~m} / \mathrm{s}$

\section{EXPERIMENTAL RESULTS}

The new data processing methods described in Section 2 has been used to process the obtained experimental data set in order to evaluate the void ratio and longitudinal mean velocity fields.

\section{3.a Void ratio distribution}

Figures $\mathrm{N}^{\circ} 15$ (a to e) show the void ratio evolution versus the relative wall distance $\mathrm{Y}^{*}=\mathrm{Y} / \delta$ for the five probed stations. $\delta$ is the local sheet thickness which corresponds to the zone where the void ratio is greater than $1 \%$. Table $\mathrm{N}^{\circ} 1$ shows the measured values of $\delta$ for the five probed stations.

\begin{tabular}{|c|c|c|c|c|c|}
\hline $\begin{array}{c}\text { Station } \\
\text { Number }\end{array}$ & 1 & 2 & 3 & 4 & 5 \\
\hline$\delta(\mathrm{mm})$ & 1,5 & 3,75 & 5,65 & 6 & 6,6 \\
\hline
\end{tabular}

Table $\mathbf{N}^{\circ} 1$ : Cavitation sheet thickness for the five probed stations 
Present results are confronted with Stutz [4] ones. For stations $\mathrm{N}^{\circ} 1$ to 3, the evolution are qualitatively equivalent. It appears that Stutz's results tend to underestimate the void ratio. At the opposite, for the last two stations $\left(\mathrm{N}^{\circ} 4\right.$ and 5$)$, the two set of results seem to be closer.

It appears also, for stations $\mathrm{N}^{\circ} 1$ and 2 , that the maximum void ratio value is obtained near the wall: the present study indicates very large $\alpha$ values, in the range of 0.9 to 0.95 . For the rear part of the cavitation sheet (stations $\mathrm{N}^{\circ} 3$ to 5 ), the maximum void ratio value seems to be shifted roughly to the middle part of the sheet, while in the wall region the void ratio falls drastically. This configuration may be explained by the influence of the re-entrant jet which will be described hereafter in this paper. 
Station N1(A)

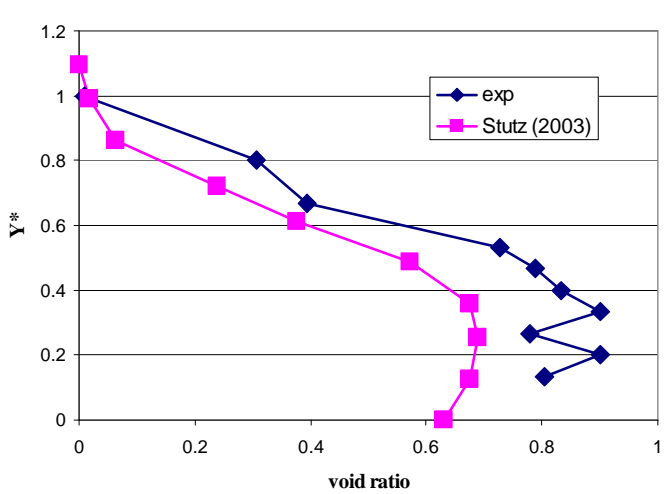

Station $\mathbf{N} 3(\mathrm{C})$

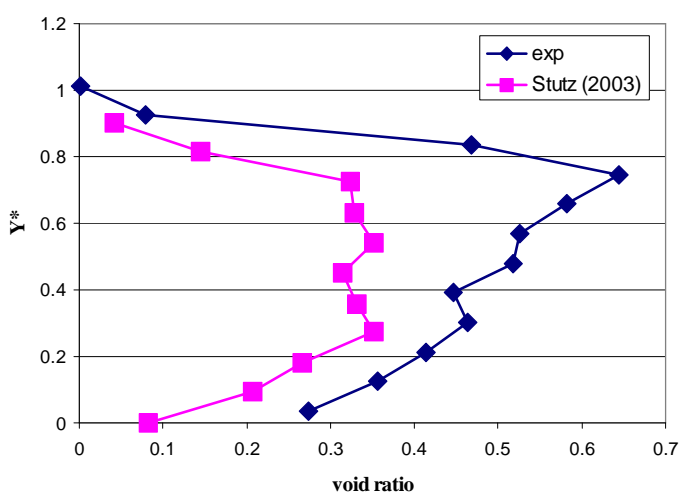

Station N2(B)

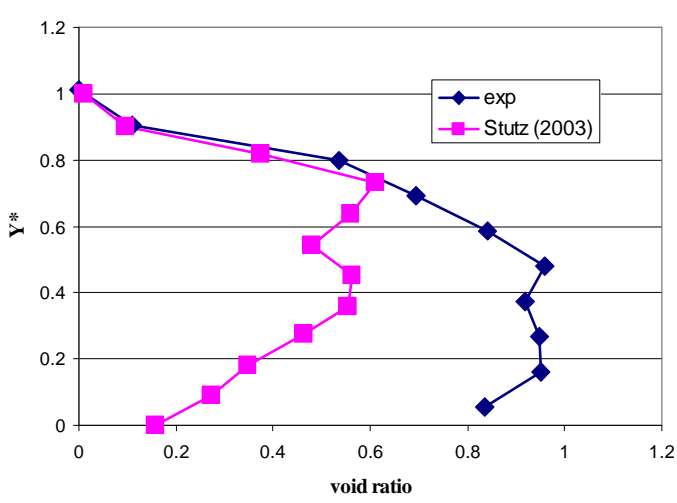

Station N4(D)

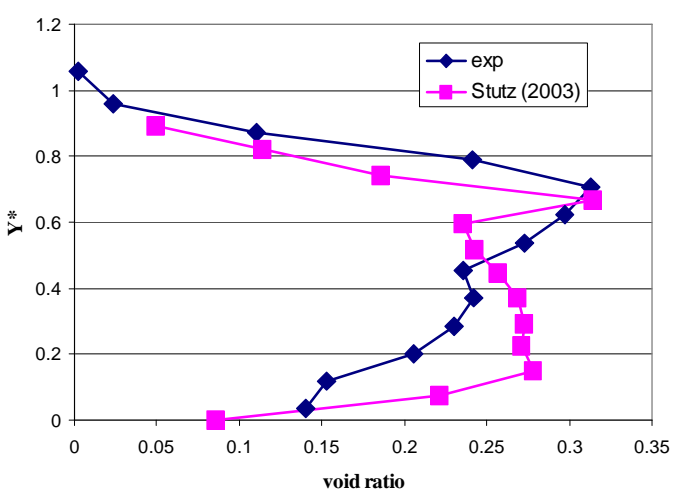

Station N5(E)

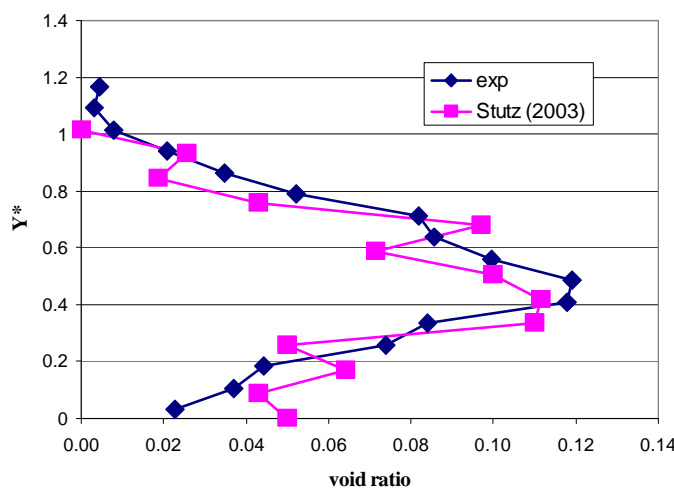

Figure $\mathbf{N}^{\circ}$ 15: Experimental void ratio profiles

Station $N^{\circ} 1(A)$; Station $N^{\circ} 2(B)$; Station $N^{\circ} 3(C)$; Station $N^{\circ} 4(D)$; Station $N^{\circ} 5(E)$

\section{$\underline{\text { 3.b Velocity fields }}$}


Figures $\mathrm{N}^{\circ} 16$ (a to e) show the spatial evolution of the longitudinal velocity for the five probed stations. Three kind of data are displayed: the results obtained by Stutz [4] concerning most probable velocities, and ones issued from the present experiments presented in terms of mean velocity (Vmean) and most probable velocity ( $\mathrm{Vmp}$ ).

At station $\mathbf{N}^{\circ} \mathbf{1}$ (figure $\mathrm{N}^{\circ} 16 \mathrm{a}$ ), considering recent data, a velocity profile close to a turbulent boundary layer type is obtained near the wall. For the intermediate region $(0.2<\mathrm{Y}<0.8 \mathrm{~mm})$, the velocity is quasi constant. It can be shown that, excepted in the external part of the sheet (for high values of $\mathrm{Y}$ ) the mean velocity (Vmean) are close to the most probable one (Vmp). This means that the turbulent field is Gaussian or near-Gaussian at this place which is close to what can be found in the core of a shear layer (a boundary layer in the present case). Obviously the external boundary corresponds to a highly intermittent zone where mean and most probable velocity diverge.

Stutz [4] results are in disagreement with the present study. Firstly, he observed in a region close to the wall $(0<\mathrm{Y}<0.4 \mathrm{~mm})$ a velocity in the range of 1 to $2 \mathrm{~m} / \mathrm{s}$ quite close to a re-entrant jet signature. After, in the upper part of the sheet, they observed a quasi boundary layer type profile.

At station $\mathbf{N}^{\circ} 2$ (figure $N^{\circ} 16 \mathrm{~b}$ ), we can observe a great disagreement between analysed data. The Vmp profile reaches the external velocity $(\sim 12 \mathrm{~m} / \mathrm{s})$ at the superior boundary of the sheet. We can also observe a constant $\mathrm{Vmp} \approx 10 \mathrm{~m} / \mathrm{s}$ zone for $(1<\mathrm{Y}<2.5 \mathrm{~mm})$ and, for lower values of $\mathrm{Y}$, a boundary layer profile is obtained, which may corresponds to the initial boundary layer observed in station $\mathrm{N}^{\circ} 1$. According to these results, a sheared zone seems to occur in the external part of the sheet in this flow region. This shear does not appear on $\mathrm{Vmp}$ profile at station $\mathrm{N}^{\circ} 1$. The Vmean profile is qualitatively comparable to the Vmp one in the external part of the sheet $(1.5<\mathrm{Y}<3.5 \mathrm{~mm})$. At the opposite, in the turbulent zone closer to the wall the difference between Vmean and Vmp increases : the strong structural difference observed between Vmean and Vmp profiles in this region seems indicate that the turbulent field is far from Gaussian form and that the re-entrant jet has an effect on the flow structure even if it is not really visible at station $\mathrm{N}^{\circ} 2$. From Stutz [4] results, a re-entrant jet may be observed at station $\mathrm{N}^{\circ} 2$, expanding until $\mathrm{Y} \sim 1.5 \mathrm{~mm}$.

In the rear part of the sheet (stations $\mathbf{N}^{\circ} \mathbf{3}, \mathbf{4}$ and $\mathbf{5}$ on figures $\mathrm{N}^{\circ} 16 \mathrm{c}$ to e) a re-entrant jet is clearly visible from Vmp profile. At station 3, we can observe a good qualitative agreement between the Vmp profiles and Stutz's [4] ones: for both studies, the re-entrant jet thickness is found equal to about $2.5 \mathrm{~mm}$. As observed before, at station $\mathrm{N}^{\circ} 2$ (figure $\mathrm{N}^{\circ} 16 \mathrm{~b}$ ), the core of a free shear layer is located at $\mathrm{Y}=2.5 \mathrm{~mm}$, near the sheet external boundary. It seems that this layer is the starting point of the detachment process of the internal sheet flow. This free shear layer is observed at station $\mathrm{N}^{\circ} 3$ in the 
range of $(2<\mathrm{Y}<3 \mathrm{~mm})$ and corresponds to the boundary between the main flow (external) and the reentrant jet.

The Vmean experimental profile is different both in shape and values than the Vmp one. Indeed, in the re-entrant jet zone the flow is strongly turbulent with a lot of large scale fluctuations (unsteadiness). The turbulent field is very complex with reversed flow, intermittent boundaries and is far away from a Gaussian one. In fact, the re-entrant jet is not well described by the Vmean profile because, in the free shear layer zone $(Y \approx 2.5 \mathrm{~mm})$, the flow is greatly intermittent and the velocity PDF in this zone showed a kind of two-state systems oscillating between a positive and a negative value of the velocity (typically Vmp switches between $\mathrm{Vmp}^{-}=-2 \mathrm{~m} / \mathrm{s}$ and $\mathrm{Vmp}^{+}=8 \mathrm{~m} / \mathrm{s}$ ). Due to this situation, in this region Vmean only represents the mean of these two values with a variable "ponderation" depending on the respective probability of occurrence of $\mathrm{Vmp}^{-}$and $\mathrm{Vmp}^{+}$at each $\mathrm{Y}$ positions. The boundary of the re-entrant jet may then be defined by the place where the occurrences of these two values on the velocity PDF are equal. In this case Vmean can be simply computed as the mean of $\mathrm{Vmp}^{-}$and $\mathrm{Vmp}^{+}$, that is $\mathrm{Vmean}=3 \mathrm{~m} / \mathrm{s}$ which corresponds roughly to $\mathrm{Y}=2.5 \mathrm{~mm}$ (see figure $\mathrm{N}^{\circ} 16 \mathrm{c}$ ).

When comparing the present Vmp profiles with Stutz one at stations $\mathrm{N}^{\circ} 4$ and 5 , we observe that both re-entrant jet thickness and velocity are found very different. These high discrepancies may be attributed to the huge difference on the observation time between the present work and Stutz's one, mainly in the re-entrant jet zone where the intermittency of the flow makes difficult the statistics convergence. Moreover, it is also possible to explain these differences by the quite drastic changes on the velocity computation algorithm performed in the present study. It is worth noting that the new velocity field structure obtained from the present experiments leads to a new flow rate repartition in the cavitation sheet as compared to the one obtained by Stutz [4].

Station N9 (A)

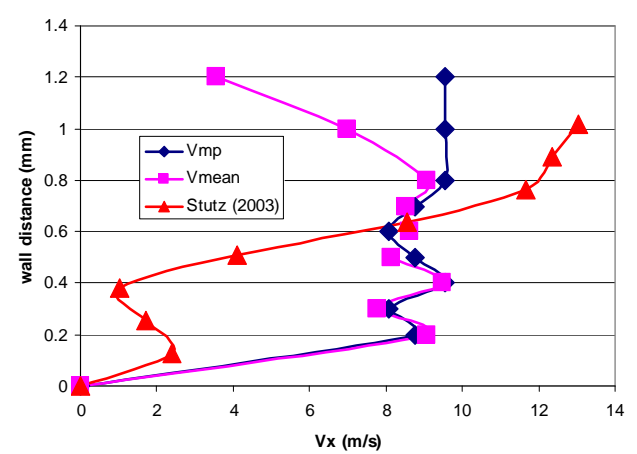

Station N2 (B)

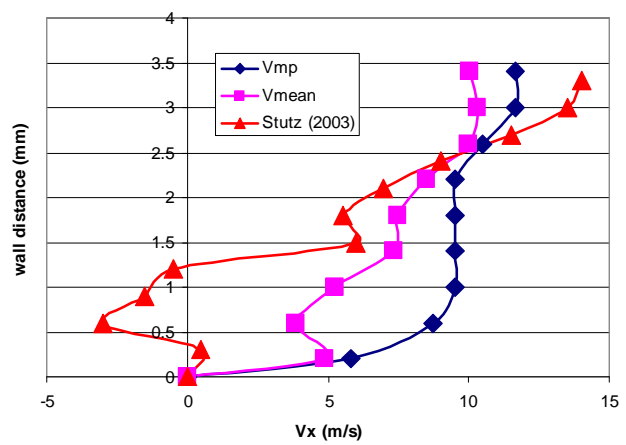



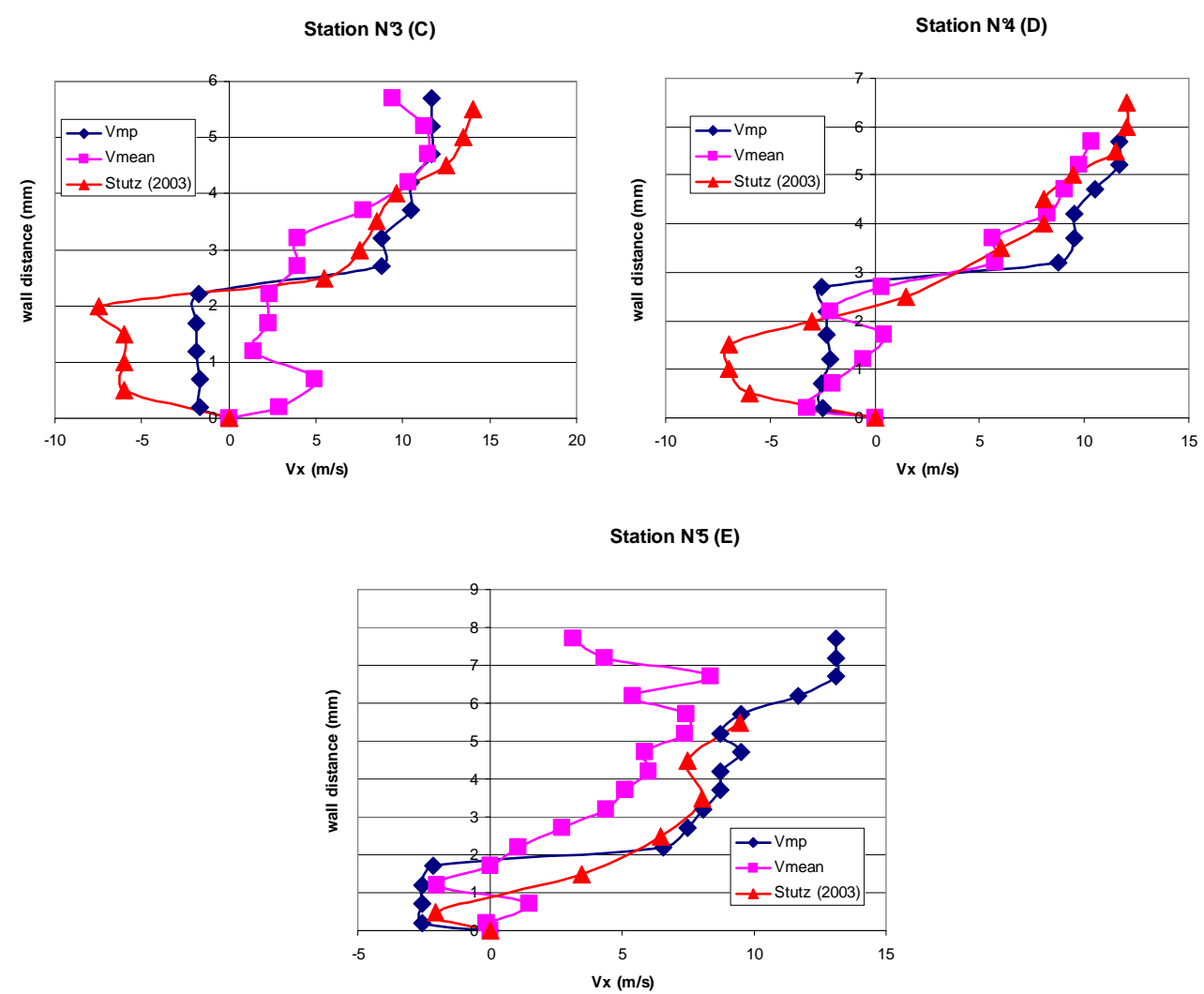

Figure $N^{\circ}$ 16: Experimental velocity profiles

Station $N^{\circ} 1(A)$; Station $N^{\circ} 2(B)$; Station $N^{\circ} 3(C)$; Station $N^{\circ} 4(D)$; Station $N^{\circ} 5(E)$

\section{3.c Flow structure}

Simultaneous analyses of void ratio and velocity fields allow to improve the study of the considered cavitating flow.

Figure $\mathrm{N}^{\circ} 17$ represents the void ratio longitudinal evolution for five values of the parameter $\mathrm{Y}^{*}$ $\left(Y^{*}=0.1,0.3,0.5,0.7\right.$ and 0.9$)$. The values $\mathrm{X}$ (horizontal axis) shown on figure 17 express the downstream distance from the venturi throat which is located at $X=0$. The position of the five probed stations is represented by the dots on the iso $\mathrm{Y}^{*}$ curves. The two isolines for $\mathrm{Y}^{*}=0.7$ and 0.9 corresponds to the external part of the sheet where the flow is running in the main flow direction everywhere in the cavitation sheet. For the other values of the parameter $\mathrm{Y}^{*}$, the flow runs in the main direction for stations $\mathrm{N}^{\circ} 1$ and 2 , and in the opposite way (reversed flow corresponding to re-entrant jet) for stations $\mathrm{N}^{\circ} 3$ to 5

Especially for $\mathrm{Y}^{*}=0.7$, it can be noted that a strong vaporisation occurs in stations $\mathrm{N}^{\circ} 1$ and 2 , followed by a less violent condensation process when entering in the recompression zone of the flow.

For the flowlines corresponding to $\mathrm{Y}^{*}=0.1$ to 0.5 (which are related to the re-entrant jet at stations $\mathrm{N}^{\circ} 3$ to 5$)$, the upstream zone $(0<\mathrm{x}<20 \mathrm{~mm})$ exhibits also a strong and fast vaporisation process, mainly between the venturi throat and the station $\mathrm{N}^{\circ}$. The downstream zone $(38<\mathrm{x}<74 \mathrm{~mm})$ 
corresponds to the re-entrant jet vaporisation zone (the flow is running in the rear direction here), which seems to be quite slower than the initial process occurring at the leading edge of the sheet. We can notice that for all the studied isolines the void ratio seems to converge to values in the range of 5 to $12 \%$ at station $\mathrm{N}^{\circ} 5$, which determines the initial condition of the re-entrant jet.

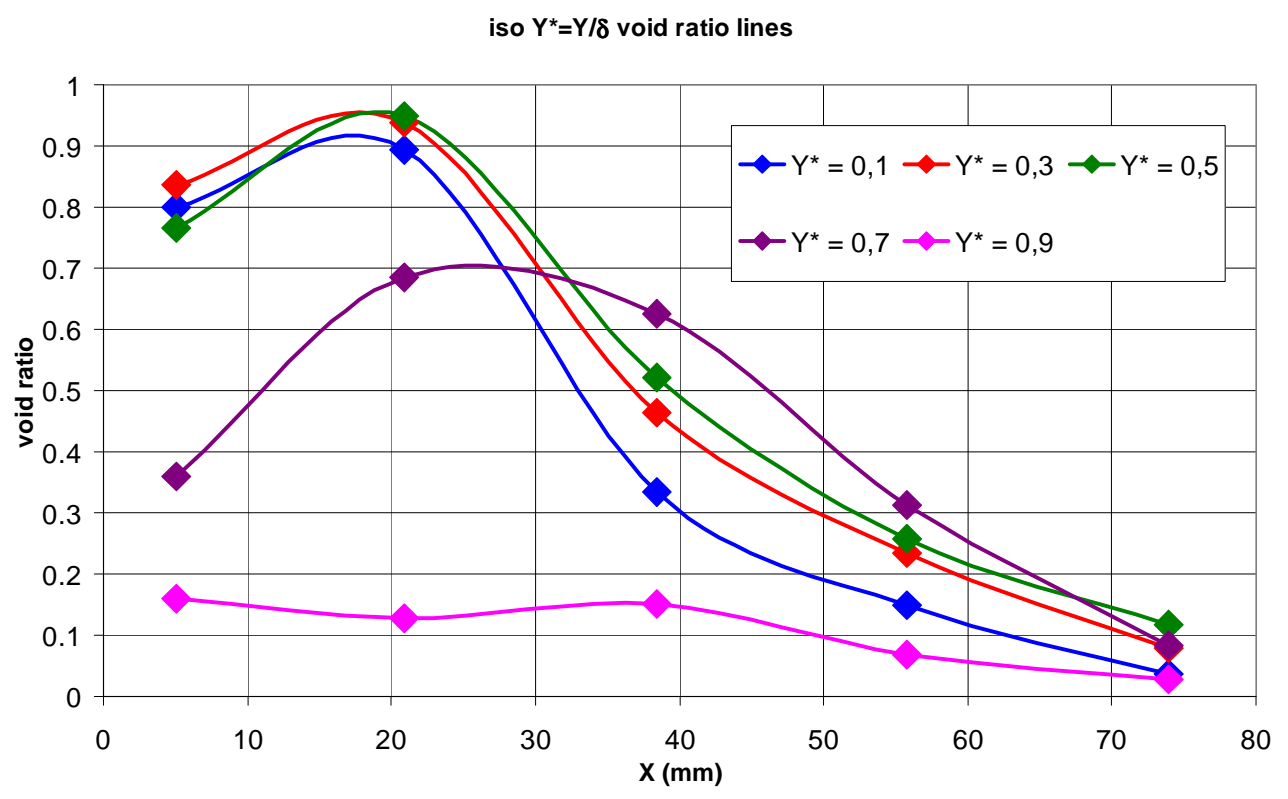

Figure $\mathrm{N}^{\circ} 17$ : Iso $\mathrm{Y}^{*}$ void ratio lines

\section{NUMERICAL CODE}

\section{4.a Multiphase Equation System}

In collaboration with Numeca International, the laboratory LEGI has implemented cavitation models in the Fine/Turbo ${ }^{\text {TM }}$ code. The numerical toll is a three-dimensional structured mesh code that solves the time dependant Reynolds-averaged Navier-Stokes equations. A detailed description of the initial code is given in (Hakimi [27]).

The governing equations are written for a homogeneous fluid. This fluid is characterized by a density that varies in the computational domain according to a barotropic state law and that is related to the void ratio defined by

$$
\alpha=\frac{\rho-\rho_{L}}{\rho_{V}-\rho_{L}} .
$$

The void ratio characterizes the volume of vapour in each cell: $\alpha=1$ means that the cell is completely occupied by vapour; inversely, a complete liquid cell is represented by $\alpha=0$. Liquid and vapour phases are characterized by their thermodynamic characteristics. On each cell, the unknowns are calculated by averaging them by the volume occupied.

In this homogeneous model, the fluxes between the two phases are implicitly treated The two phases are considered to be locally (in each cell) in dynamic equilibrium (no drift velocity).

The compressible Reynolds-Averaged Navier-Stokes equations are expressed as: 


$$
\begin{aligned}
& \frac{\partial \rho_{m}}{\partial t}+\nabla \cdot\left(\rho_{m} \mathbf{u}_{m}\right)=0 \\
& \frac{\partial \rho_{m} \mathbf{u}_{m}}{\partial t}+\nabla \cdot\left(\rho_{m} \mathbf{u}_{m} \otimes \mathbf{u}_{m}\right)=-\nabla\left(p_{m}\right)+\nabla \cdot\left(\bar{\tau}_{m}\right)+\rho_{m} \mathbf{F}_{m}
\end{aligned}
$$

where $\bar{\tau}_{m}$. is the shear stress tensor, $\mathbf{F}_{\mathrm{m}}$ the body forces and $\rho_{\mathrm{m}}$ the mixture density, defined as $\rho_{m}=\alpha \rho_{v}+(1-\alpha) \rho_{L}$

Each pure phase is considered incompressible.

The space discretization is based on a cell-centered finite-volume approach. The numerical fluxes are computed with the central scheme stabilized by the Jameson dissipation (Jameson et al., [28]).

Time accurate resolutions use the dual time stepping approach. Pseudo-time derivative terms are added to the equations. They march the solution towards convergence at each physical time step. The explicit four stage Runge-Kutta time stepping procedure is used to advance the solution to steady state.

A complete description of the numerical scheme is presented by (Coutier-Delgosha et al, [21]).

\section{4.b. Preconditioned Navier-Stokes Equations}

In the case of low-compressible or incompressible flows, the time-marching algorithm converges very slowly and the used of a low Mach number preconditioner in the Navier-Stokes equations is required (Turkel [29], Hakimi [27]). It is based on the modification of the pseudo-time derivative terms in the governing equations. Such modifications have no influence on the converged results, since these terms are of no physical meaning, and converge to zero. The resulting preconditioned system is controlled by pseudo-acoustic eigenvalues much closer to the advective speed, reducing the eigenvalue stiffness and enhancing the convergence.

Using this preconditioner in the case of steady calculations the set of equations becomes:

$$
\iiint_{V} \bar{\Gamma}^{-1} \frac{\partial \mathbf{P}}{\partial \tau} d V+\iint_{\Sigma} \mathbf{F} . \mathbf{n} d \Sigma=\iiint_{V} \mathbf{S} d V
$$

The flux vector $\mathbf{F}$ can be decomposed in an inviscid and a viscous part, $\mathbf{F}=\mathbf{F}_{\mathrm{I}}-\mathbf{F}_{\mathrm{V}}$

with

$$
\mathbf{F}_{I}=\left(\begin{array}{c}
\rho \mathbf{u} \\
\rho(\mathbf{u} \otimes \mathbf{u})+p \overline{\bar{I}}
\end{array}\right) \quad \text { et } \quad \mathbf{F}_{V}=\left(\begin{array}{c}
0 \\
\bar{\tau}
\end{array}\right)
$$

The vector $\mathbf{S}$ represents the source term. In turbomachinery, it contains contribution of Coriolis and centrifugal forces and is given by:

$$
\mathbf{S}=\left(\begin{array}{c}
0 \\
(-\rho)[2 \boldsymbol{\omega} \times \mathbf{u}+(\boldsymbol{\omega} \times(\boldsymbol{\omega} \times \mathbf{r}))]
\end{array}\right)
$$

with $\omega$ the angular velocity of the relative frame of reference

introducing the preconditioning matrix $\overline{\bar{\Gamma}}^{-1}$ and associated variables vector $\mathbf{P}$ : 
$\mathbf{P}=\left(\begin{array}{c}p_{g} \\ \mathbf{u}\end{array}\right)$ and $\overline{\bar{\Gamma}}^{-1}=\left(\begin{array}{cc}\frac{1}{\beta^{2}} & 0 \\ \frac{(1+\alpha) \mathbf{u}}{\beta^{2}} & \rho\end{array}\right)$

$\mathrm{p}_{\mathrm{g}}$ is the gauge (relative) pressure, $\mathbf{u}$ is the velocity vector, $\alpha$ and $\beta$ are the preconditioning parameters. In the present applications, $\alpha=-1$ and $\beta$ depends of the reference velocity, and is defined by : $\beta^{2}=\beta_{0} . U_{\text {ref }}^{2}$ with $\beta_{0}=3$ in our case.

The eigenvalues of the preconditioned system become:

$\lambda_{1,2}=\mathbf{u} \cdot \mathbf{n}$ and $\lambda_{3,4}=\frac{1}{2}\left[\mathbf{u} \cdot \mathbf{n}(1-\alpha) \pm \sqrt{(\mathbf{u} \cdot \mathbf{n}(1-\alpha))^{2}+4 \mathbf{n}^{2} \beta^{2}}\right]$

where $\mathbf{n}$ is the normal vector to the elementary surface dS.

For more details concerning the used preconditionner, see (Coutier-Delgosha et al., [22]).

\section{4.c. Turbulence Models}

In the present work, the Yang-Shih k-epsilon model (Yang \& Shih [30]) with extended wall functions (Hakimi et al. [31])has been applied.

\section{4.d. Barotropic Model}

To model cavitation phenomenon and to enclosure the governing equations system, a barotropic state law introduced by (Delannoy and Kueny [23]) has been implemented in Fine/Turbo ${ }^{\mathrm{TM}}$ code (Pouffary [5,6,19], Coutier-Delgosha et al. $[21,22]$ ). The fluid density (and so the void fraction) is controlled by a law $\rho(\mathrm{p})$ that links explicitly the mixture fluid density to the local static pressure as represented by Figure 18.

This law is mainly controlled by its maximum slope, which is related to the minimum speed of sound $c_{\min }$ in the mixture. The parameter Amin controls this slope:

$$
A M I N^{2}=\frac{\rho_{L}-\rho_{V}}{2} c_{\min }^{2}
$$




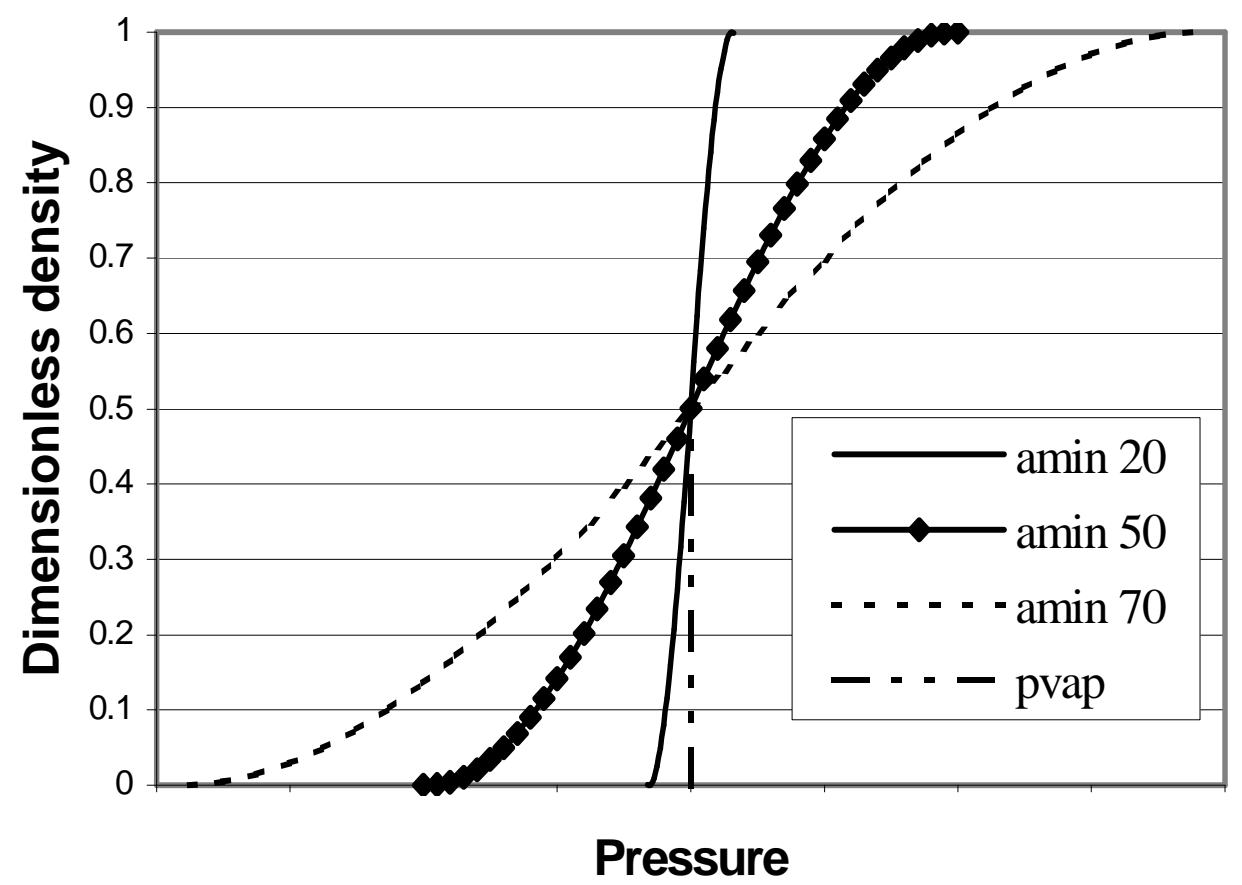

Figure $\mathrm{N}^{\circ}$ 18: Influence of Amin parameter on barotropic law.

Table 2 presents Amin values used for cold water calculations presented in this paper Thermodynamic effects have been neglected and the energy equation was not taken into account. Works are in progress in order to implement new cavitation models including thermal effects (Rolland et al. [32]).

\begin{tabular}{|c|c|c|c|c|c|}
\cline { 2 - 6 } \multicolumn{1}{c|}{} & \begin{tabular}{c}
$\mathrm{T}$ \\
\multicolumn{1}{c|}{}
\end{tabular} & $\begin{array}{c}\rho_{\mathrm{v}} \\
\mathrm{kg} / \mathrm{m}^{3}\end{array}$ & $\begin{array}{c}\rho_{\ell} \\
\mathrm{kg} / \mathrm{m}^{3}\end{array}$ & $\begin{array}{c}\text { Amin } \\
\mathrm{m} / \mathrm{s} .\left(\mathrm{kg} / \mathrm{m}^{3}\right)^{0.5}\end{array}$ & $\begin{array}{c}\mathrm{c}_{\min } \\
\mathrm{m} / \mathrm{s}\end{array}$ \\
\hline \multirow{3}{*}{ Water } & & & & 70 & 3.13 \\
& \multirow{3}{*}{293} & 0,0173 & 998 & 50 & 2.24 \\
& & & & 20 & 0.89 \\
\hline
\end{tabular}

Table 2: Physical parameters and tested Amin values

\section{EXPERIMENTS-SIMULATION CONFRONTATION IN COLD WATER}

\section{5.a. Calculation Conditions}

The studied case, presented in Section 1 , is a steady sheet with a length of about $80 \mathrm{~mm}$, at $\mathrm{U}_{\text {inlet }}=10.8 \mathrm{~m} / \mathrm{s}$. The reference density is the liquid density equal to $998 \mathrm{~kg} / \mathrm{m}^{3}$. Steady calculations are led with the k- $\varepsilon$ turbulence model, with extended wall functions. The 2D mesh, illustrated in Figure 15, contains 9861 nodes, 173 in the flow direction and 57 in the normal direction. The $y+$ values vary from 18 to 50 . The boundary conditions are mass flow for inlet condition and static pressure imposed at outlet. 


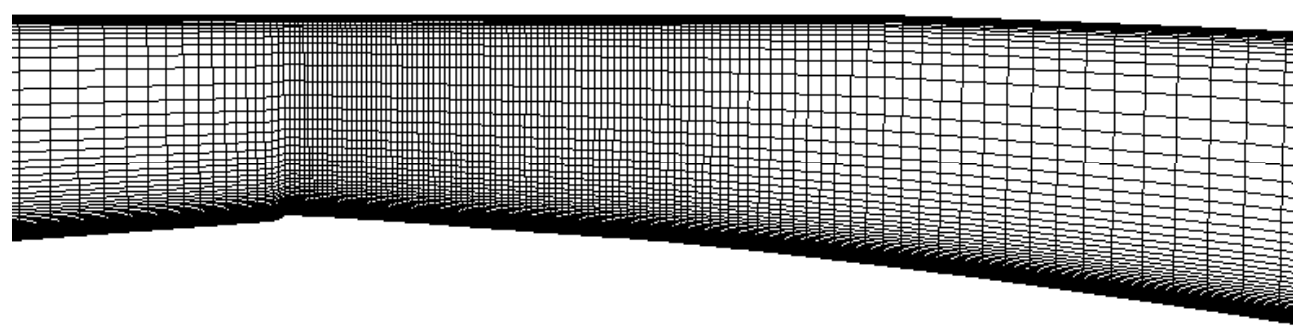

Figure $N^{\circ} 19$ : View of mesh for $k-\varepsilon$ computational

\section{5.b. Global Analyses}

Initially, we have analysed the cavity global behaviour, mainly the sheet length as a function of the cavitation number. In order to carry out comparisons with experimental data, three calculations with different Amin values are considered in this paper. They have been conducted by trial and error to obtain almost the same sheet length. A smooth variation of the inlet cavitation number is observed (see Table $\mathrm{N}^{\circ} 3$ ).

The influence of Amin on the sheet vapour volume seems weak, except for high values of Amin, where the volume becomes larger. It may be explained by the fact that for large Amin, the upper part of the sheet interface is more diffuse, as shown in Figure 20. Local analysis, presented in the next section, has confirmed these tendencies.

\begin{tabular}{|c|c|c|c|c|}
\hline Amin & 70 & 50 & 20 & $\exp$ \\
\hline Sigma (inlet) & $\begin{array}{c}0.68 \\
3\end{array}$ & $\begin{array}{c}0.64 \\
2\end{array}$ & $\begin{array}{c}0.60 \\
0\end{array}$ & $\begin{array}{c}\mathbf{0 . 5 4} \\
\mathbf{7}\end{array}$ \\
\hline $\mathrm{L}_{\text {sheet }}(\mathrm{mm})$ & 79.8 & 80.2 & 81.5 & $\mathbf{8 0}$ \\
\hline $\begin{array}{c}\text { Vapour } \\
\text { volume } \\
\left({ }^{*} 10-4 \mathrm{~m} 3\right)\end{array}$ & $\begin{array}{c}4.00 \\
5\end{array}$ & $\begin{array}{c}3.74 \\
1\end{array}$ & $\begin{array}{c}3.69 \\
9\end{array}$ & \\
\hline
\end{tabular}

Table $\mathbf{N}^{\circ}$ 3: Comparison of experimental and simulation values of the sheet length $(\mathrm{L})$ versus the cavitation parameter $\sigma$

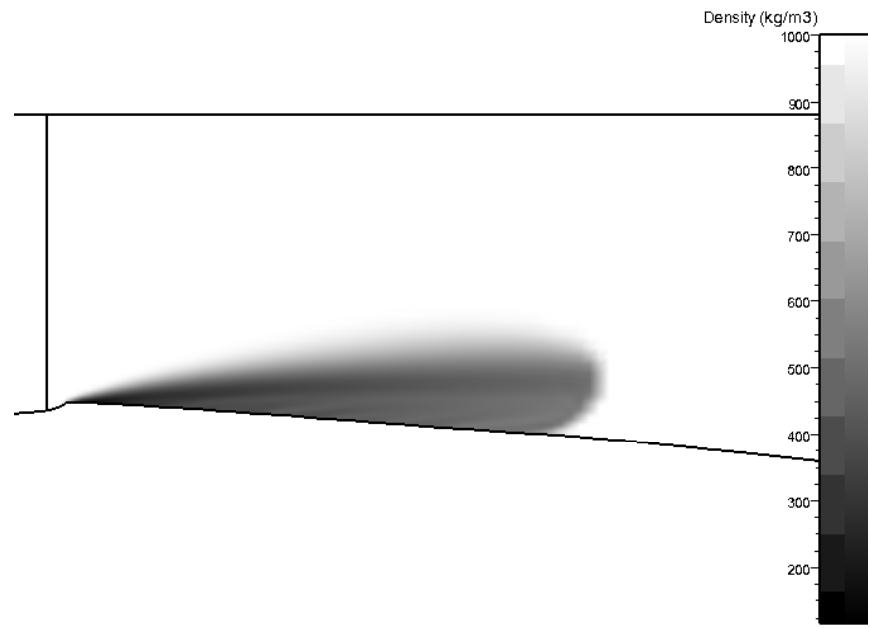

Figure $\mathrm{N}^{\circ}$ 20: Density field inside the cavity for $\mathbf{A m i n}=\mathbf{5 0}$ 
The defined sheet length used for representing the computational results has been determined by the length of the isoline corresponding to a void ratio $\alpha=0.3$. This criterion is argued by the fact that it corresponds to the area of maximal value of the density gradient (see Figure 21). As a matter of fact, because of the strong density gradient at the enclosure of the sheet, the sheet length varies weakly as a function of the interface criterion. A test showed that, for a void ratio between $10 \%$ and $30 \%$, the sheet length variation was about $2 \%$.

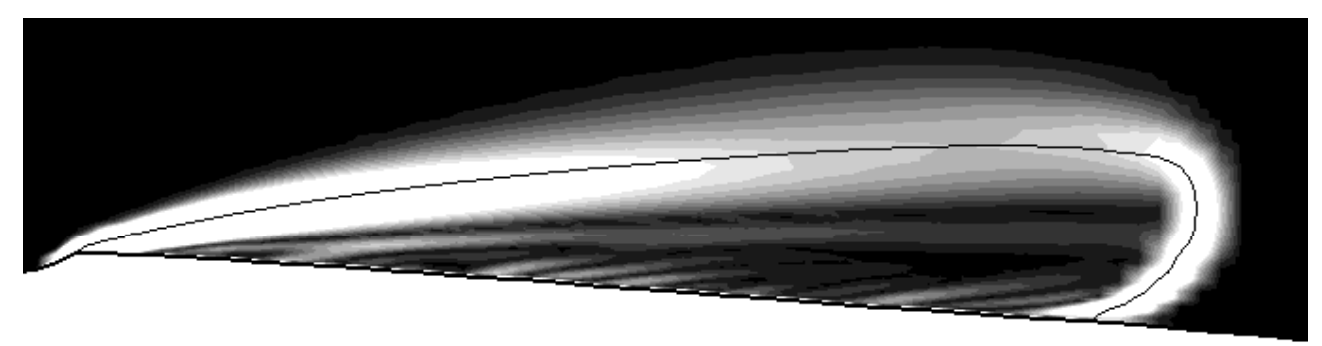

Figure $N^{\circ}$ 21: Magnitude of density gradient $\left(0\right.$ to $\left.10^{6} \mathrm{~kg} / \mathrm{m}^{4}\right)$ and iso-line $\alpha=0.3$

$\mathrm{L}_{\text {sheet }} \sim \mathbf{8 0} \mathbf{~ m m}, A \min =\mathbf{5 0}$

\section{5.c. Local Analyses}

Complementary analyses concern local void ratio and velocity profiles comparisons inside the cavity. The void ratio and velocity profiles are obtained for the five stations defined in the Section 1 of the paper. New experimental results will be confronted to the numerical simulation data obtained in the present work as described in part 2 and 3 of this paper.

\section{5.c.1 Void ratio distribution}

Figures $\mathrm{N}^{\circ} 22$ (a to e) show the void ratio evolution for the five probed stations. Present experimental results are compared to computations data obtained with three different values of the Amin (Amin=20, 50 and 70) parameter in the barotropic law used to model the phase change during vaporization and condensation process. 
Station $\mathrm{N}^{\circ}$ (A)

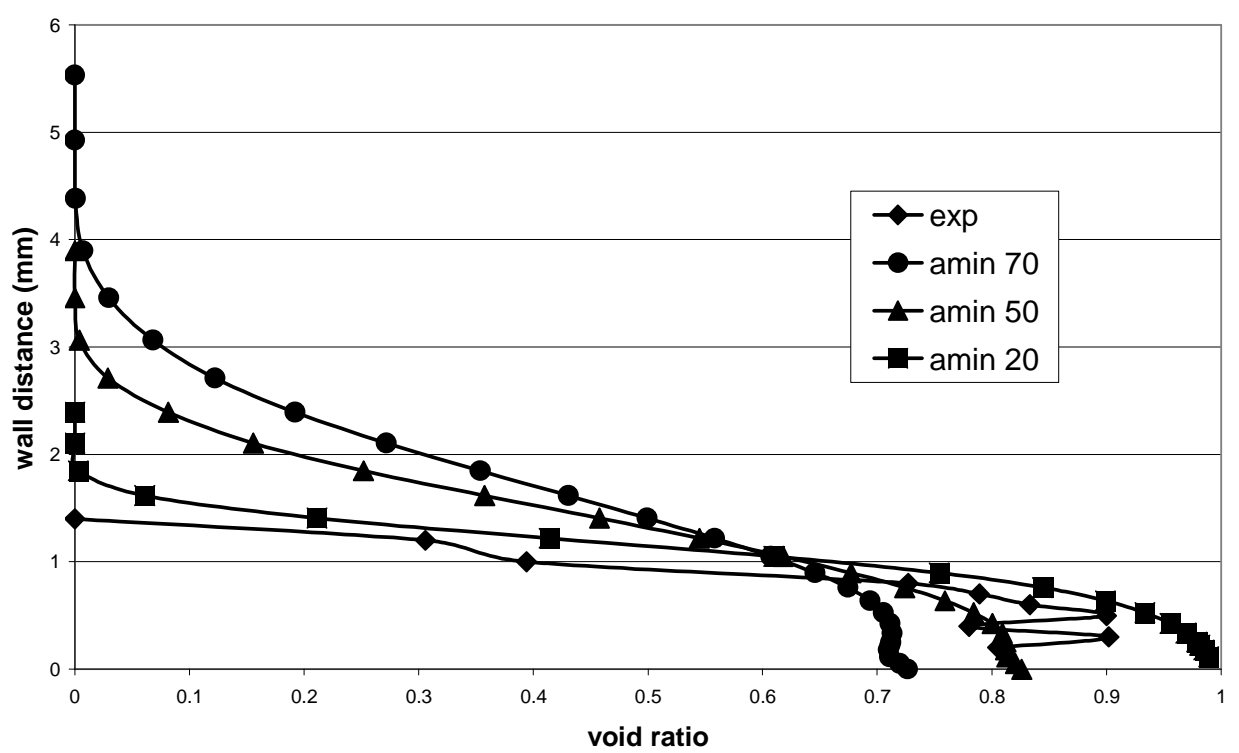

Station N2 (B)

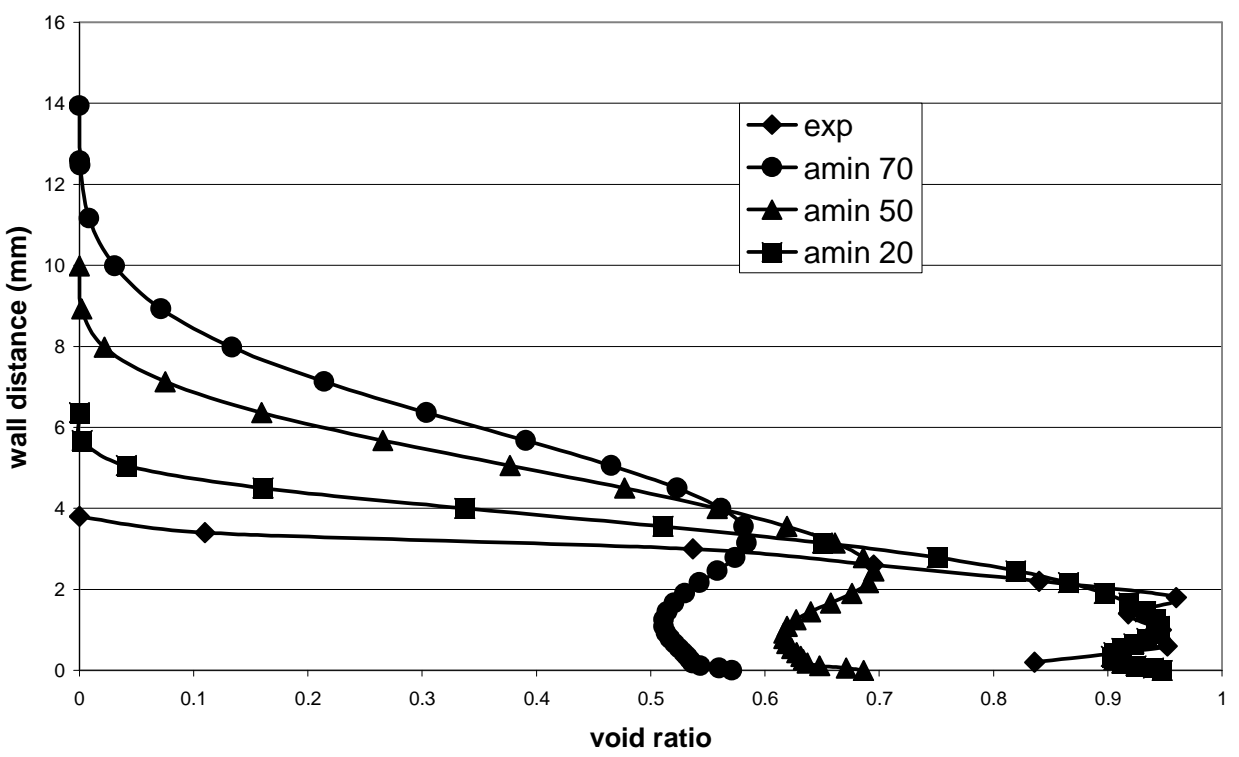


Station N3 (C)

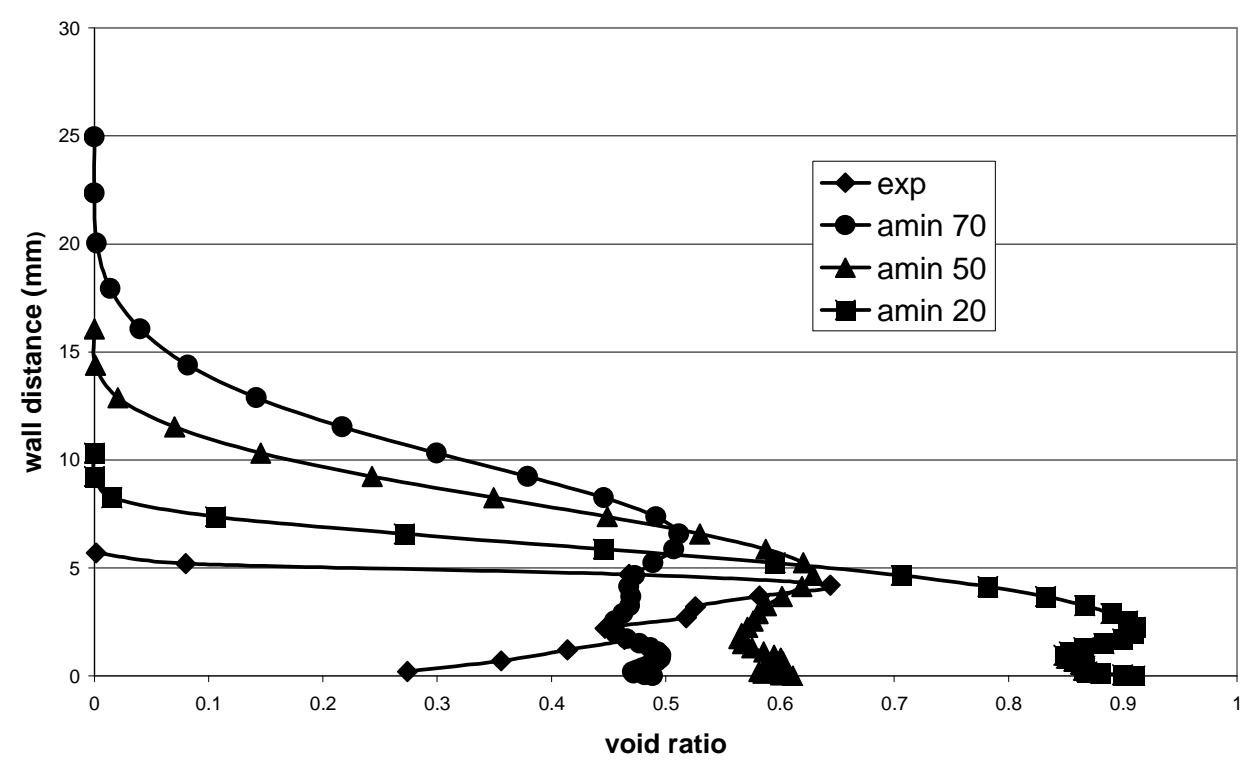

Station N4 (D)

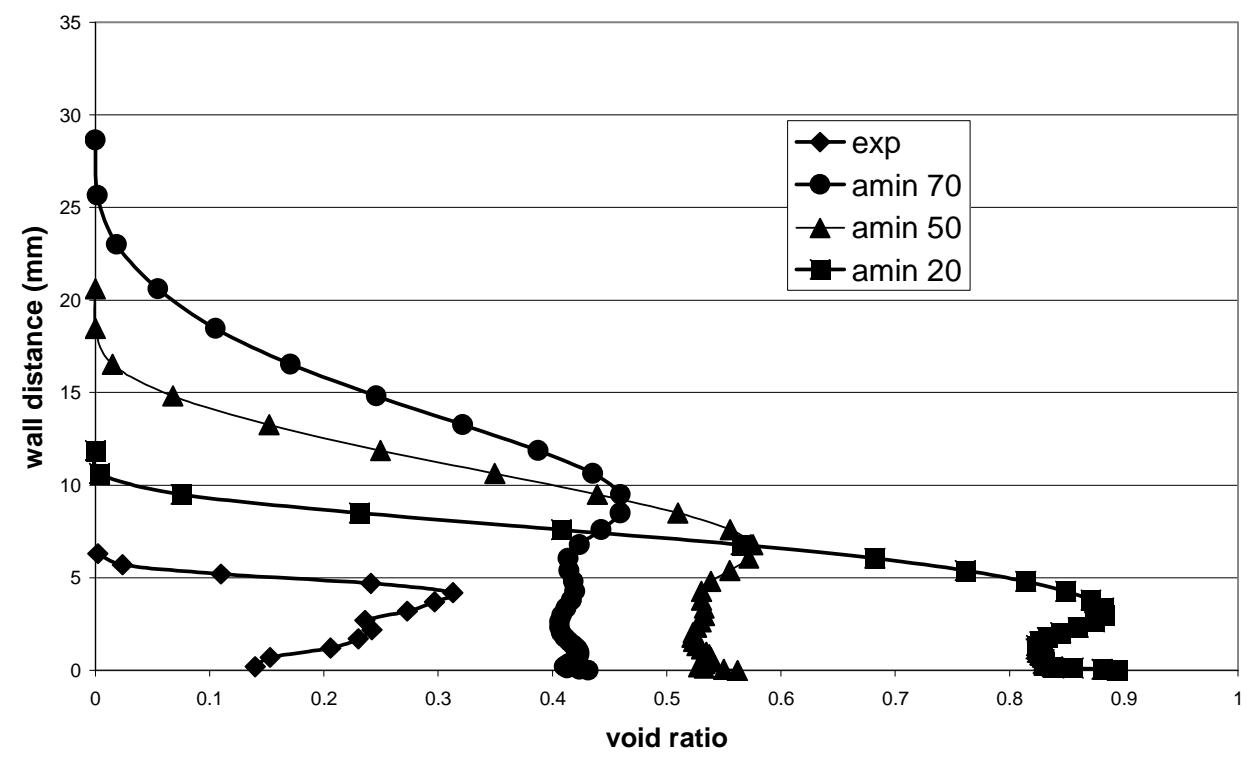




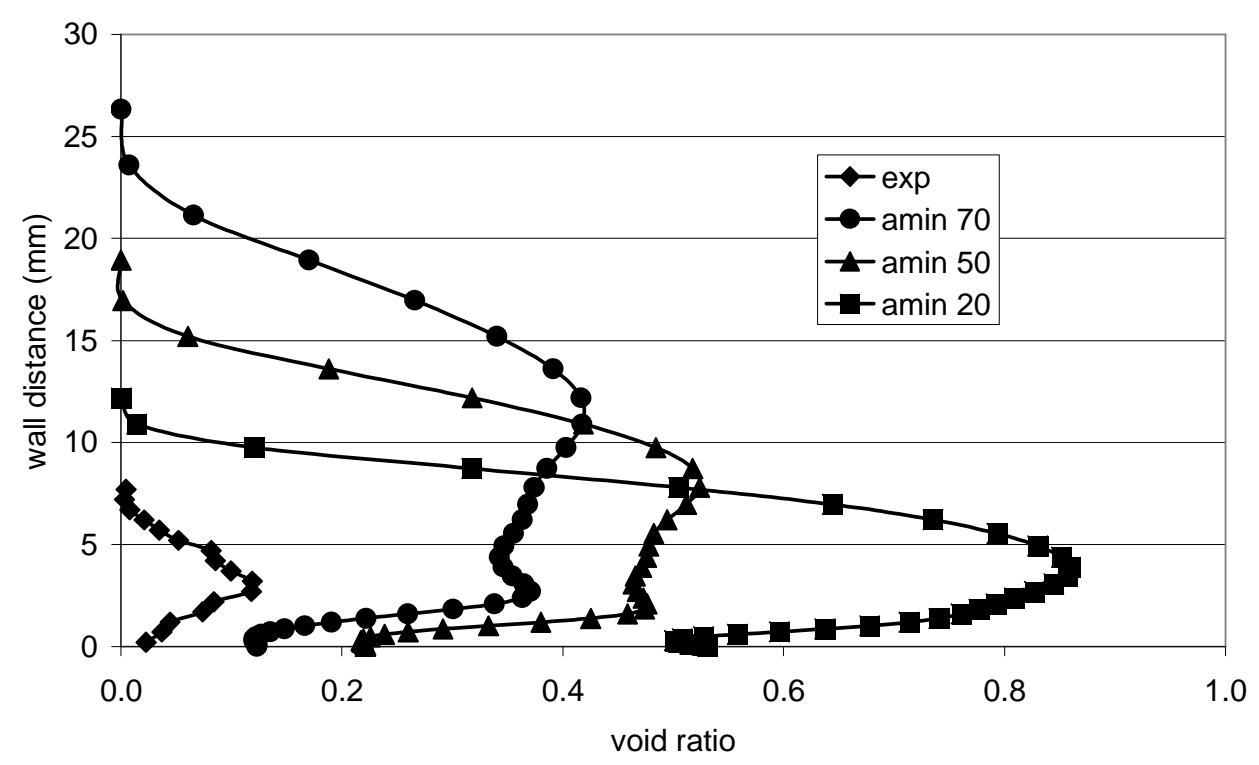

FigureN ${ }^{\circ} 22$ : Void ratio profiles: Comparison between present experiments and simulation results

At stations $\mathrm{N}^{\circ} 1$ and 2 (figures $\mathrm{N}^{\circ} 22$ a and b) a satisfactory agreement is obtained between experimental void ratio values and those issued from computations with Amin=20. It can be also shown that an increase on the Amin value leads to an underestimation of the void ratio near the wall and also predicts an overestimation of the sheet thickness as compared to the experimental observations. For example at station $\mathrm{N}^{\circ} 1$, we measured a sheet thickness $\delta=1.5 \mathrm{~mm}$, while computations using Amin $=50$ and 70 respectively give value of 3 to $4 \mathrm{~mm}$ for $\delta$. It seems that almost in the initial part of the sheet (stations $\mathrm{N}^{\circ} 1$ and 2) the barotropic law with Amin=20 (leading to a minimum sound velocity $\mathrm{Cmin}=0.89 \mathrm{~m} / \mathrm{s}$ ) is able to model quite accurately the flow behaviour in the leading part of the sheet where the flow is stable, with no counter-current component and with a relatively high void ratio due to the strong vaporisation process occurring here. At the opposite, from stations $\mathrm{N}^{\circ} 3$ to 5 the situation is different. While going downstream, the disagreement between experiments and computations increases culminating at station $\mathrm{N}^{\circ} 5$ where the discrepancies on the maximum value of the void ratio may reach $800 \%$ in the worse case (here, Amin $=20$ ). Computations both overestimate void ratio and sheet thickness in this flow zone.

\section{5.c.2. Flow velocity fields}

We can explain the precedent remarks by analysing figures $\mathrm{N}^{\circ} 23$ (a to e), where velocity profiles are presented for the five probed stations. On these figures, the velocities issued from the 
present experiment (Vmean and Vmp) are compared to those obtained by computations with Amin=20, 50 and 70. The analysis is split in two parts. the first one concerns stations $\mathrm{N}^{\circ} 1$ and 2 and the second one, the stations $\mathrm{N}^{\circ} 3$ to 5 .

Station No1 (A)

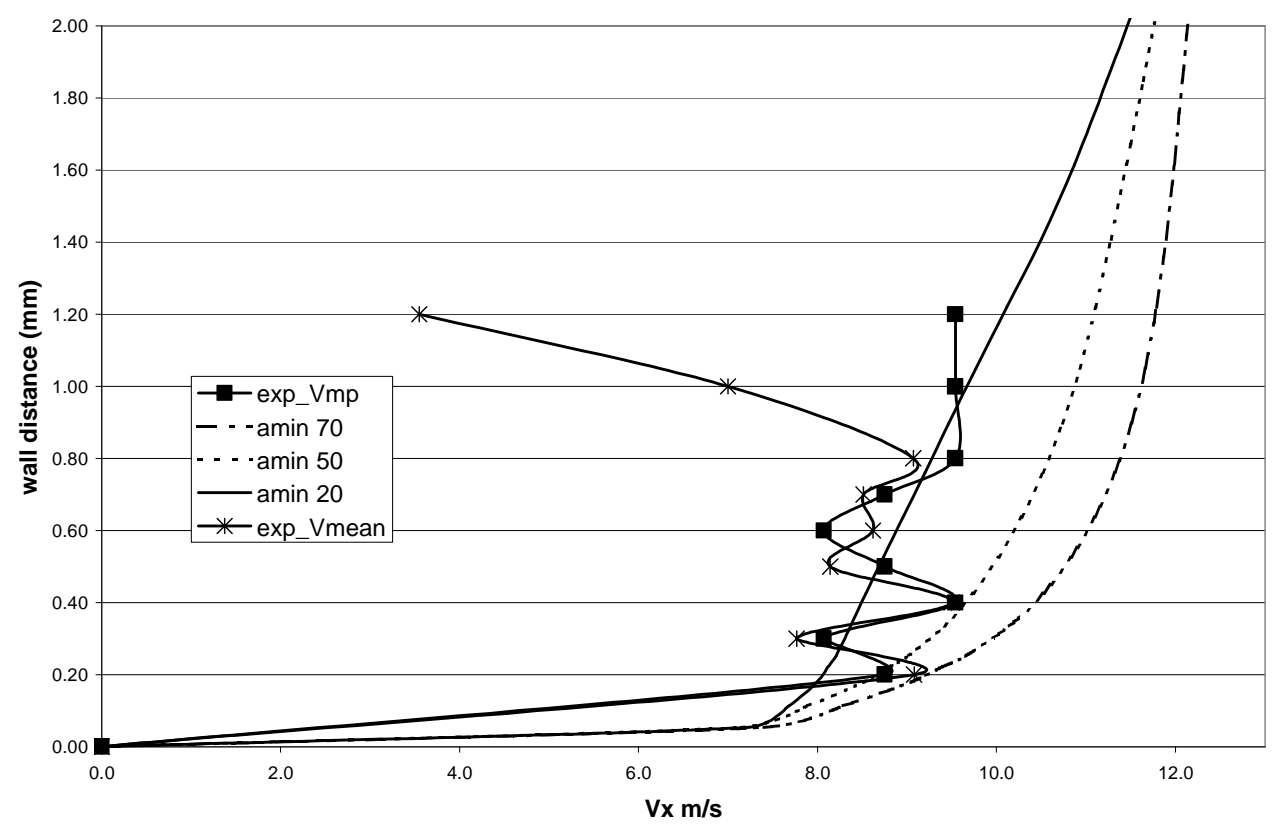

Station N2 (B)

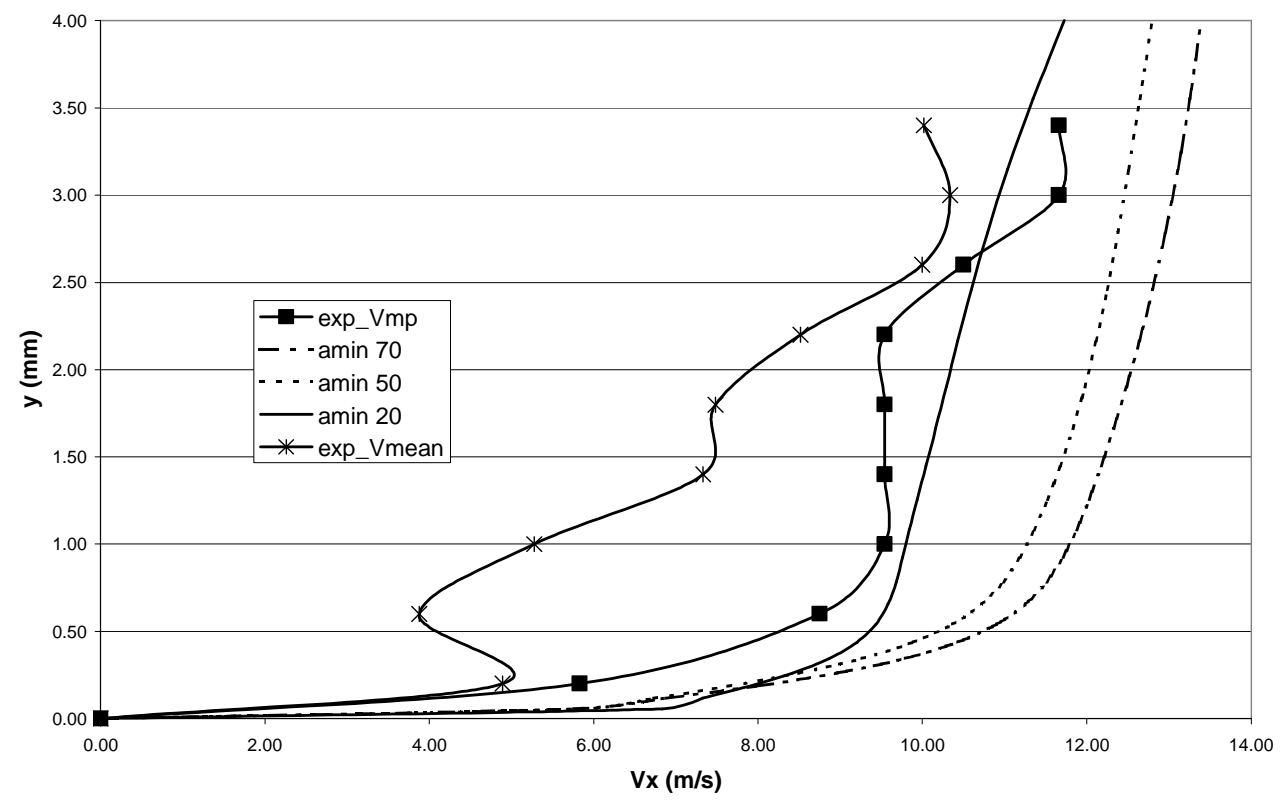


Station N3 (C)

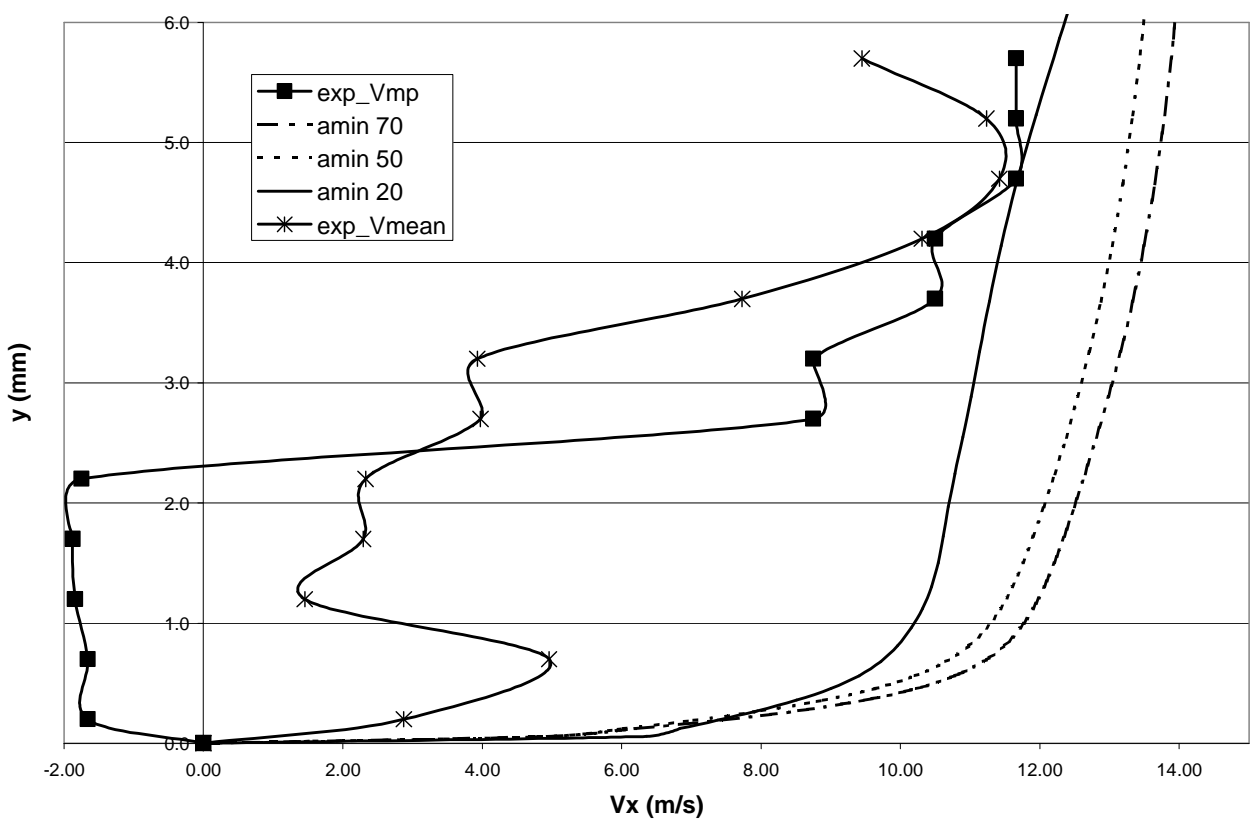

Station N4 (D)

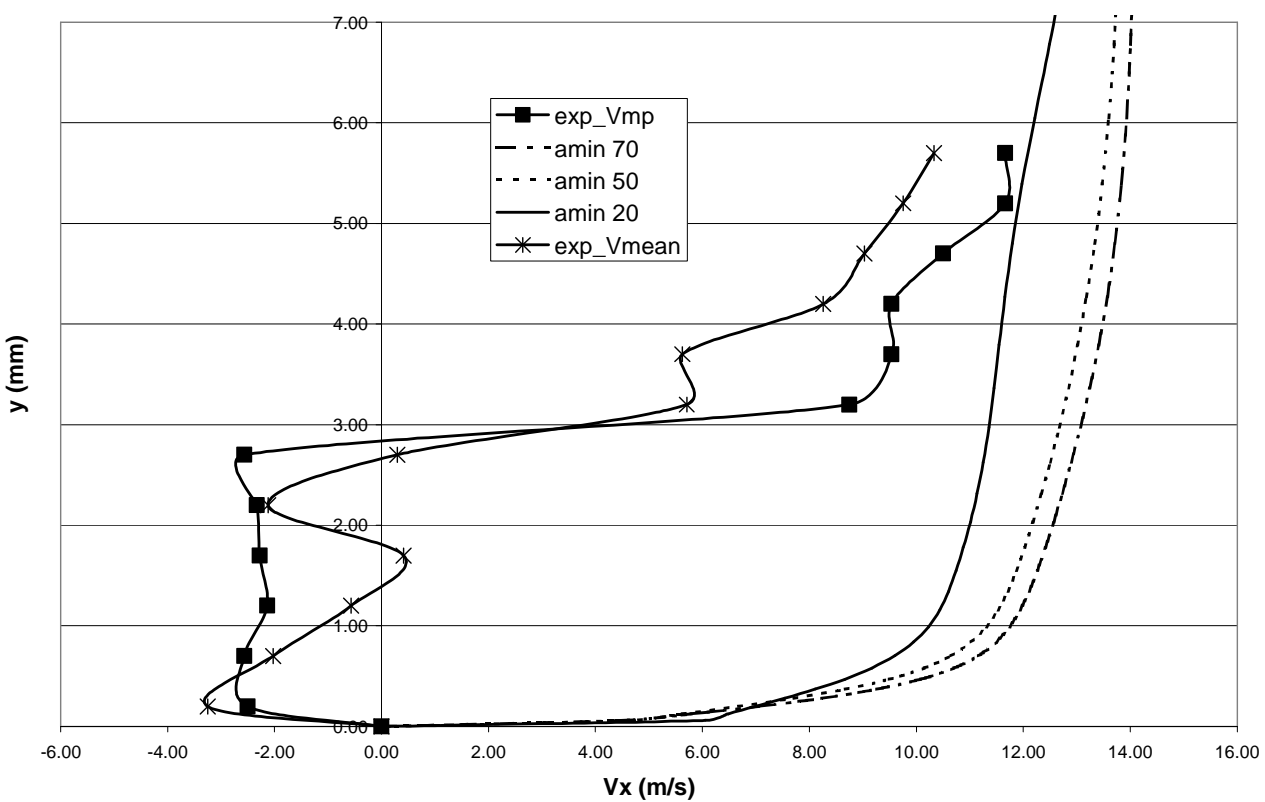




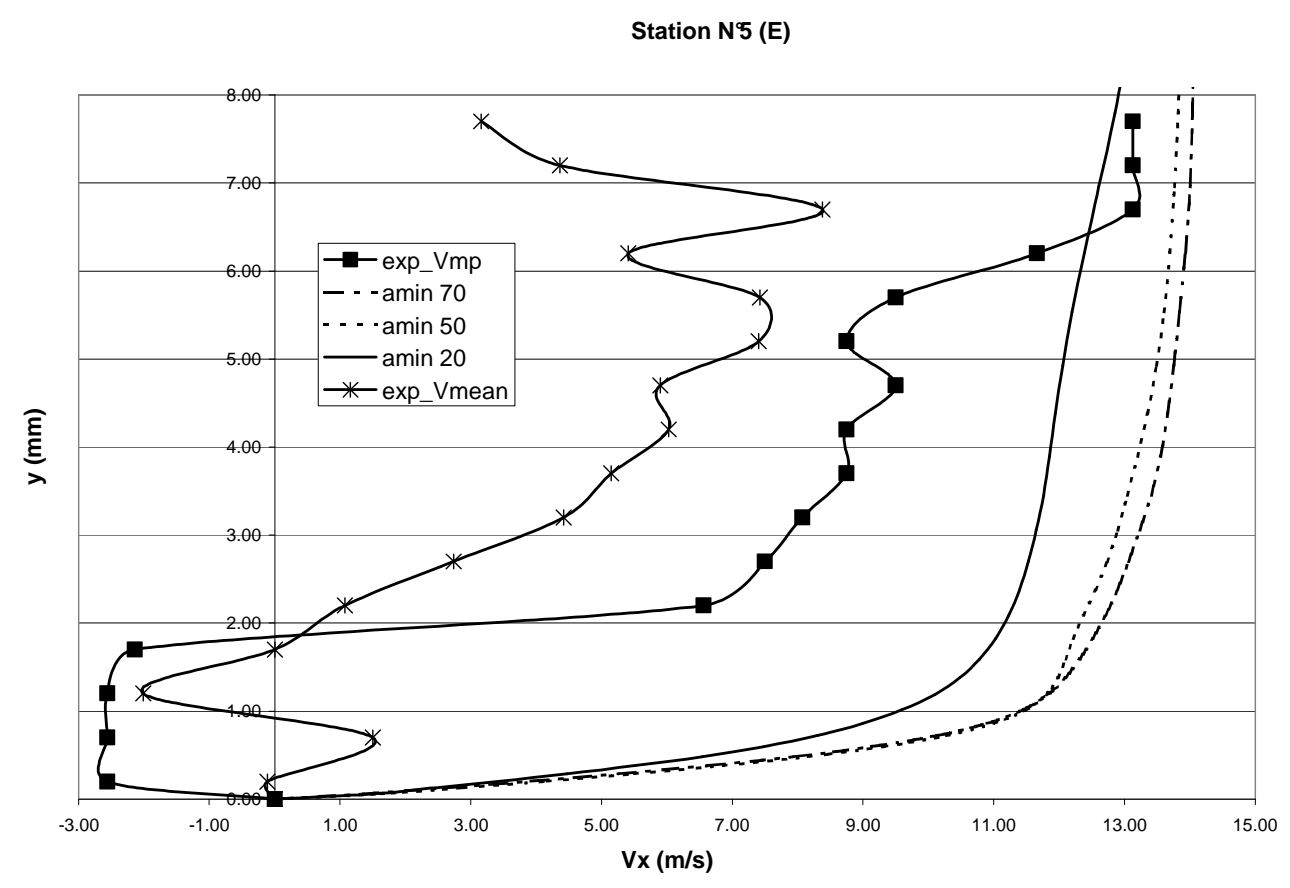

Figure $\mathbf{N}^{\circ}$ 23: Velocity profiles: Comparison between experimental and simulation results Station $N^{\circ} 1(A)$; Station $N^{\circ} 2(B)$; Station $N^{\circ} 3(C)$; Station $N^{\circ} 4(D)$; Station $N^{\circ} 5(E)$

Simulations results exhibits a strong sensibility on the value of the Amin parameter. However, the velocity profiles are qualitatively comparable and are close to turbulent boundary layer type profile. It is found that the $A m i n=20$ profile seems to best fit the experimental data at station $\mathrm{N}^{\circ} 1$.

At station $\mathrm{N}^{\circ} 2$, the comparison between experimental and numerical velocity profiles lead us to the conclusion that the simulation performed with $A \min =20$ is the one that fits better the experimental results (at least concerning the Vmp profile). However, the computed profiles are of turbulent boundary layer type . It differs from the experimental, both on the velocity values obtained and on the shape of the profiles. It can also be noticed that in the station $\mathrm{N}^{\circ} 2$, the maximum values for void ratio are attained, showing that the vaporisation phase ends near station $\mathrm{N}^{\circ} 2$ and that the Vmp profile seems to be a precursor of the ones which will be obtained downstream due to the effect of the adverse pressure gradient imposed by the flow geometry. (This fact is firstly illustrated in figure $\mathrm{N}^{\circ} 23 \mathrm{c}$ where the experimental and computational velocity profiles are represented).

Numerical simulation at station $\mathrm{N}^{\circ} 3$ (figure $\mathrm{N}^{\circ} 23 \mathrm{c}$ ) always show boundary layer type profiles. The Amin=20 case is the less bad, but none simulation is able to predict the re-entrant jet structure. Concerning stations $\mathrm{N}^{\circ} 4$ and 5 (figures $\mathrm{N}^{\circ} 23 \mathrm{~d}$ and e) the situation is similar to the one described for station $\mathrm{N}^{\circ} 3$. We can then confirm that the purely stationary aspect of the simulation used here is not 
able to accurately describe the rear part of the cavitation sheet because it does not take into account the strong unsteady aspects of this flow, mainly due to the re-entrant jet phenomenon.

\section{5.c.3. Wall pressures}

In the context of the present experimental study, the mean wall pressures were also measured for nine probed stations including the five stations inside the cavitation sheet (where void ratio and velocity measurements were performed) and also four other stations placed downstream in the wake of the sheet in order to describe the pressure recovery process after the cavitating zone. The sensor was an absolute one. We use a piezoelectric sensor DRUCK model $\mathrm{N}^{\circ} \mathrm{PMP} 4070$ with a maximum range of $70000 \mathrm{~Pa}$. Its relative precision is $\pm 0.027 \%$ giving then an absolute precision of $\pm 19 \mathrm{~Pa}$.

Figure $\mathrm{N}^{\circ} 24$ represents the mean wall pressure longitudinal evolution. The ratio $\frac{\left(p-p_{v}\right)}{p_{v}}$ , where $\mathrm{p}$ is the local wall pressure and $\mathrm{p}_{\mathrm{v}}$ is the vapor pressure, is plotted versus $\mathrm{x}-\mathrm{x}_{\mathrm{i}}$, where $\mathrm{x}-\mathrm{x}_{\mathrm{i}}$ is the distance between the measuring station and the entry section $\left(\mathrm{S}_{\mathrm{i}}\right)$. This experimental result is confronted on figure $\mathrm{N}^{\circ} 24$ with the simulation result obtained with Amin=20.

\section{mean wall pressure}

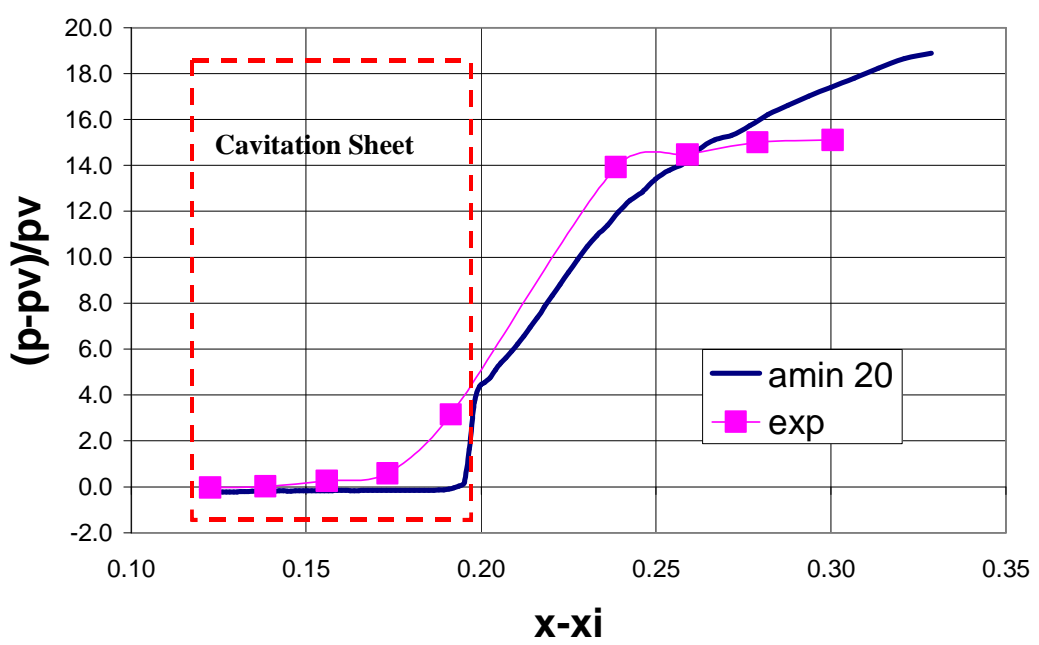

Figure $\mathbf{N}^{\circ}$ 24: Longitudinal mean wall pressure evolution: Comparison between experimental and simulation results

It can be shown that in the initial part of the sheet (until station $\mathrm{N}^{\circ}$ ) the numerical prediction fit quite well with measurements giving a wall pressure very close to the vapor pressure. This is not surprising because in all the present paper it has been observed that this zone is well described by the present simulation in terms of void ratio and velocity profiles. At the opposite, in the rear part of the 
sheet (station $\mathrm{N}^{\circ} 3$ to 9 ) results are diverging. The presence of the re-entrant jet which is not taken into account in the computation leads to a more rapid recompression process than the one predicted by numerical simulation. The stationary approach used in the present numerical simulations not only ignore the re-entrant jet dynamics but also imposed, by the mean of the barotropic law, a direct relation between the void ratio and the pressure without take into account vaporisation and condensation delays. That's why this model predicts that all the cavitating zone with high void ratio will be at a pressure very close to the vapor pressure $p_{v}$ until the sheet closure region (between stations $\mathrm{N}^{\circ} 5$ and 6), where a brutal recompression is predicted by the numerical simulations in contradiction with experimental results.

The pressure gradient in the recompression zone between stations $\mathrm{N}^{\circ} 5$ and 7 is quite well predicted by simulations. Further downstream for stations $\mathrm{N}^{\circ} 7$ to 9 , in the wake area, experimental data exhibits a constant pressure zone linked to the convective wake of rotational structures ejected at the trailing edge of the cavitation sheet due to the re-entrant jet dynamics. In this region, numerical simulations indicate a turbulent boundary layer velocity profile related to the adverse pressure gradient. As a matter of fact, the calculated wall pressure illustrates the pressure gradient imposed by the venturi geometry and does not take into account the unsteady aspects of the flow at the trailing edge of the cavitation sheet.

\section{CONCLUSION}

From double probe measurements and numerical calculations, we have analysed the global and the local behaviour of a cavitating flow through a Venturi geometry. For a quasi-steady cavitation sheet with a length of about $80 \mathrm{~mm}$, we have evaluated void ratio and velocity fields for cold water cavitation.

Experimental measurements and data treatment have been improved for cold water tests. The new method proposed for data analysis leads to a better evaluation of local behaviour of steady and unsteady cavitation.

The applied barotropic model, if associated with a stiff slope (corresponding to $c_{\min } \sim 1 \mathrm{~m} / \mathrm{s}$ for cold water), seems to well predict local behaviour in the steady areas of cavitation. Although the global behaviour of the sheet seems steady, experimental data show a re-entrant jet which creates small cloud shedding. In the zones influenced by the re-entrant jet, unsteady calculations are required to better simulate cavitation behaviour. Numerical works are in progress to carry out unsteady calculations and to analyse the influence of physical models on cavitating flow behaviour simulated. 


\section{ACKNOWLEDGMENTS}

The authors wish to express their gratitude to the French space agency CNES and to the SNECMA company to support this research. The authors wish also to express their gratitude to NUMECA International for its cooperation to the development of the numerical code.

\section{REFERENCES}

[1] Stutz B., Reboud J.L. , "Two-phase flow structure of sheet cavitation”, Phys. Fluids vol 9 (12) pp 3678-3686, 1997a.

[2] Stutz B., Reboud J.L., "Experiments one unsteady cavitation”, Exp. In Fluids, Flight. 22, pp 191-198, 1997b.

[3] Stutz B., Reboud J.L., "Measurements within unsteady cavitation”, Experiments in Fluids, $\mathrm{n}^{\circ} 29, \mathrm{pp} 545-552,2000$

[4] Stutz B., "Influence of Roughness one the Two-Phase Flow Structure of Sheet Cavitation", J of Fluids Eng., vol. 125, pp 652-659, 2003.

[5] Pouffary B. Fortes-Patella R., Reboud J.L. "Numerical simulation of 3D cavitating flows : Analysis of cavitation head drop in turbomachinery", ASME Fluids Engineering Divison Summer Meeting and Exhibition, Houston USA, June 2005a

[6] Pouffary B. Fortes-Patella R., Reboud J.L. "Numerical analysis of cavitation instabilities in inducer blade cascade", ASME Fluids Engineering Divison Summer Meeting and Exhibition, Houston USA, June $2005 b$

[7] Laberteaux K. R., and Ceccio S.L., « Flow in the Closure Region of Closed Partial Attached Cavitation » Proceedings of the Third International Symposium on Cavitation, J.M. Michel and H. Kato, eds., Grenoble, France, Vol. 1, pp. 197-202, 1998.

[8] Le Q., Franc J.P., and Michel J.M. "Partial Cavities: Global Behavior and Mean Pressure Distribution” ASME J. Fluids Eng., vol. 115, pp. 243-248, 1993.

[9] Callenaere M., Franc J.P., Michel J.M. and Riondet M., “The Cavitation Instability Induced by the Development of a Re-entrant Jet”, J. Fluid Mech., vol 444, pp. 223-256, 2001.

[10] Kamono H., Kato H., Yamaguchi H. and Miyanaga M., "Simulation of Cavity Flow by Ventilated Cavitation on a Foil Section”, ASME, New-York, ASME-FED-153, pp. 183-189, 1993.

[11] Ceccio S.L. and Brennen C.E., "Observation of the Dynamics and Acoustics of Travelling Bubble Cavitation”, J. Fluid Mech., vol 233, pp. 633-660, 1991.

[12] Iyer, C.O., Ceccio, S.L., "The influence of developed cavitation on the flow of a turbulent shear layer", Physics of Fluids, Vol. 14, N¹0, October 2002.

[13] Dular M., Bachert R., Stoffel B., Sirok B., "Experimental evaluation of numerical simulation of cavitating flow around hydrofoil“", European Journal of Mechanics B/Fluids, Vol. 24, pp. 522-538, 2005. 
[14] Stutz B., Legoupil S., Woo R., „Measurements within cloud cavitation by means of X-Ray attenuation device“,ASME Fluids Engineering Divison Summer Meeting and Exhibition, Montreal, Quebec, Canada, July 14-18, 2002.

[15] Hassan, W., Legoupil, S., Barre, S., Rebattet, C. "Dynamic vapour fraction measurement in ariane 5 inducer by x-rays" Proceedings of FEDSM2005, 2005 ASME Fluids Engineering Division Summer Meeting and Exhibition, Houston, TX, USA, June 19-23, 2005a

[16] Hassan, W., Legoupil, S., Cambellen, D., Barre, S. "Dynamic Localization of Vapour Fraction in Ariane 5 Inducer by X-Rays Tomography" 2005 IEEE Nuclear Science Symposium and Medical Imaging Conference, Porto-Rico, October 23-29, 2005b

[17] Reboud J-L., Stutz B. and Coutier O., "Two-phase flow structure of cavitation : experiment and modelling of unsteady effects", 3rd Int. Symp. on Cavitation, Grenoble, France, April 1998.

[18] Reboud J-L., Coutier-Delgosha O., Pouffary B., Fortes-Patella R., "Numerical simulations of unsteady cavitating flows: some applications and open problems", Proceedings of CAV 2003 Symposium, Invited lecturer, Osaka. November 2003.

[19] Pouffary B., Fortes-Patella R., Reboud J.L., "Numerical simulation of cavitating flow around a 2D hydrofoil: a barotropic approach”, 5th Int. Symp. on Cavitation, Osaka, Japan, 2003.

[20] Coutier-Delgosha, O., Reboud J.L., Delannoy, Y., "Numerical simulation of the unsteady behaviour of cavitating flows", Int. Journal for Numerical Methods in Fluids, Vol. 42, Issue 5, pp. 527-548, 2003.

[21] Coutier-Delgosha O., Fortes-Patella R., Reboud J.L., Hakimi N., Hirsch C., "Numerical simulation of cavitating flow in 2D and 3D inducer geometries", Int. Journal for Numerical Methods in Fluids, Vol. 48, Issue 2, pp. 135-167, 2005a.

[22] Coutier-Delgosha O., Fortes-Patella R., Reboud J.L., Hakimi N., Hirsch C., "Stability of preconditioned Navier-Stokes equations associated with a cavitation model", Computers \& Fluids, Vol. 34, Issue 3, pp. 319-349, March 2005b.

[23] Delannoy Y., Kueny J.L., "Two phase flow approach in unsteady cavitation modelling”, Cavitation and Multiphase Flow Forum, ASME-FED vol 98, pp 153-158, 1990.

[24] Stutz B., "Analyse de la structure diphasique et instationnaire de poches de cavitation”, $\mathrm{Ph}$. D. Thesis, INPG, CREMHYG Laboratory, 1996.

[25] Serisawa, A., Kataoka, I., Michivik, M., and Park, S. H., ."Turbulence Structure of Air-Water Bubbly Flow - Measuring Techniques“, Int. J. Multiphase Flow, Vol. 2, pp. 221-233, 1975.

[26] Revankar, S. T., and Ishii, M., "Local Interfacial Area Measurement in Bubbly Flow”, Int. J. Heat Mass Transfer, Vol. 35, pp. 913-925, 1992.

[27] Hakimi N., "Preconditioning methods for time dependent Navier-Stokes equations", Ph.D.Thesis, Vrije Univ., Brussels, 1998. 
[28] Jameson A., Schmidt W., Turkel E., "Numerical solution of the Euler equations by finite-volume methods using Runge-Kutta time stepping schemes”, AIAA Paper 81-1259, June 1981.

[29] Turkel E, "Preconditioning methods for solving the incompressible and low speed compressible equations”, Journal of Comp. Phys., vol 72, pp.277-298, 1987.

[30] Yang Z., Shih T.H., “A k-e model for tubulence and transitional boundary layer”, Near-wall Turbulent Flows, R.M.C. So.,C.G. Speziale and B.E. Launder (Editors), Elsevier-Science Publishers B. V., pp165-175, 1993.

[31] Hakimi N., Hirsch, C., Pierret S., "Presentation and application of a new extended k- $\varepsilon$ model with wall functions", ECCOMAS, Barcelona, September 2000.

[32] Rolland, J., Barre, S., Goncalves, E., Fortes-Patella, R., "Experiments and Modelling of Cavitating Flows in Venturi, Part I: Stable Cavitation”. Sixth International Symposium on Cavitation, CAV2006, Wageningen, The Netherlands, September 2006 